\title{
DE LA PIEDRA DE RUSKIN AL ADOBE DE VELARDE: INVESTIGACIÓN Y DESARROLLO CI+D] EN LA CONSERVACIÓN DEL PATRIMONIO EDIFICADO PERUANO. LA CÁTEDRA BRUNO ROSELLI COMO MODELO DE COLABORACIÓN PÚBLICO, PRIVADO Y ACADÉMICO ${ }^{(*)}$
}

\author{
FROM RUSKIN'S STONES TO VELARDE'S ADOBES: RESEARCH AND DEVELOPMENT (REDJ] IN THE \\ PRESERVATION OF PERUVIAN BUILT HERITAGE. THE BRUNO ROSELLI CHAIR AS A MODEL OF \\ PUBLIC, PRIVATE AND ACADEMIC PARTNERSHIP \\ HÉCTOR ABARCA TORRES ${ }^{[\star]}$
}

Fecha de recepción: 27 de abril de 2017

Fecha de aprobación: 30 de julio de 2017

\begin{abstract}
RESUMEN
Los conceptos actuales de gestión del patrimonio edificado instituidos por ICOMOS y el Consejo de Europa están avanzando más allá de la capacidad de nuestro sistema de gestión patrimonial. Sin embargo, muchos proyectos de investigación en el campo de la conservación se están llevando adelante mediante la colaboración entre universidades peruanas y reconocidas instituciones internacionales dedicadas a la protección del patrimonio edificado. Este estudio lista varias de estas experiencias nacionales, así como otras internacionales, que ayudan a entender la conservación como un proyecto de Investigación y Desarrollo $(\mathrm{I}+\mathrm{D})^{(* * *)}$ que conecte socios públicos, privados y académicos a través de la Cátedra Bruno Roselli, un programa avanzado de investigación que permitirá agilizar y apoyar a alcanzar un enfoque contemporáneo a la gestión del patrimonio construido peruano.
\end{abstract}

\section{PALABRAS CLAVE}

Investigación y Desarrollo, información patrimonial, colaboración pública-privada-académica, arquitectura de tierra

\begin{abstract}
The current concepts on management of the built Heritage led by ICOMOS and the European Council are moving forward beyond the building capacity of our current system of heritage management. However there are a lot of complex projects that are being carried out in partnerships between Peruvian academic institutions and major international conservation organizations. This paper lists some of the local and foreign experiences that can help to create a shift that will allow conservation as Research and Development $(\mathrm{R} \& \mathrm{D})^{(* * *)}$ ventures to connect public, private and academic partners through the Bruno Roselli Chair, a research program that will streamline and support a contemporary approach of the Peruvian built heritage.
\end{abstract}

\section{KEYWORDS}

Research and Development, heritage information, public-private-academic partnership, earthen architecture

(*) El interés en este tema nació durante las clases del curso de postgrado de Proyectos Culturales para el Desarrollo en el campus del Centro Internacional de Formación de la OIT en Turín (2004) al escuchar las experiencias de los profesores en gestión del patrimonio en varias partes del mundo. Luego, por estudios o trabajo me he involucrado con profesionales e instituciones dedicadas a la conservación del patrimonio en distintas ciudades y países, y he venido acumulando información de experiencias que puedan ser aplicables en el Perú y ahora presento en este documento. ${ }^{* *}$ Arquitecto por la Universidad Nacional de Ingeniería, con maestría en Diagnóstico y Rehabilitación de Edificaciones por la Universidad de Sevilla, y especialización en Regeneración Urbana por la Universidad Politécnica de Lublin. Además, posee posgrados en Gestión de Edificaciones Históricas en la Universidad de Lund, en Proyectos Culturales para el Desarrollo por la Universidad de Turín y el Centro Internacional de Formación de la OIT, y en métodos de participación Charrette por la Universidad de Harvard y el National Charrette Institute. Ha trabajado para varias firmas de arquitectura canadienses y para el Instituto de Conservación Getty. Ha colaborado con el Museo de Arte Moderno de Nueva York y ha contribuido a publicaciones en el Perú, Ecuador, Canadá e Italia. Actualmente reside en Vancouver y está colegiado en la Asociación de Arquitectos de la Columbia Británica. Contacto: hrabarca@yahoo.com $\left.{ }^{(* * *}\right)$ Los proyectos I+D son parte de las políticas estatales que vinculan las áreas de la investigación en Ciencia e Ingeniería en relación a un objetivo productivo. En el presente caso estas áreas las dan la tecnología del adobe histórico, la ingeniería sísmica, la extensión de la vida útil de la obra restaurada y la gestión del patrimonio.

$\left.{ }^{* * * *}\right)$ Los proyectos de Investigación y Desarrollo se identifican por las siglas R\&D en inglés e I+D en español. 
devenir Vol. 4, N8, JULIO - DICIEMBRE 2017, pP. 49-74 - Estudios I ISSN 2312-7562 I E-ISSN 2616-4949

UNIVERSIDAD NACIONAL DE INGENIERÍA, LIMA

Figura 1. Muro de adobe con base de ladrillo y cimiento de piedra limpio de desprendimientos y material extraño. Restauración de la Casa del Alabado (s. XVII), Quito, 2006. Archivo fotográfico de Héctor Abarca.

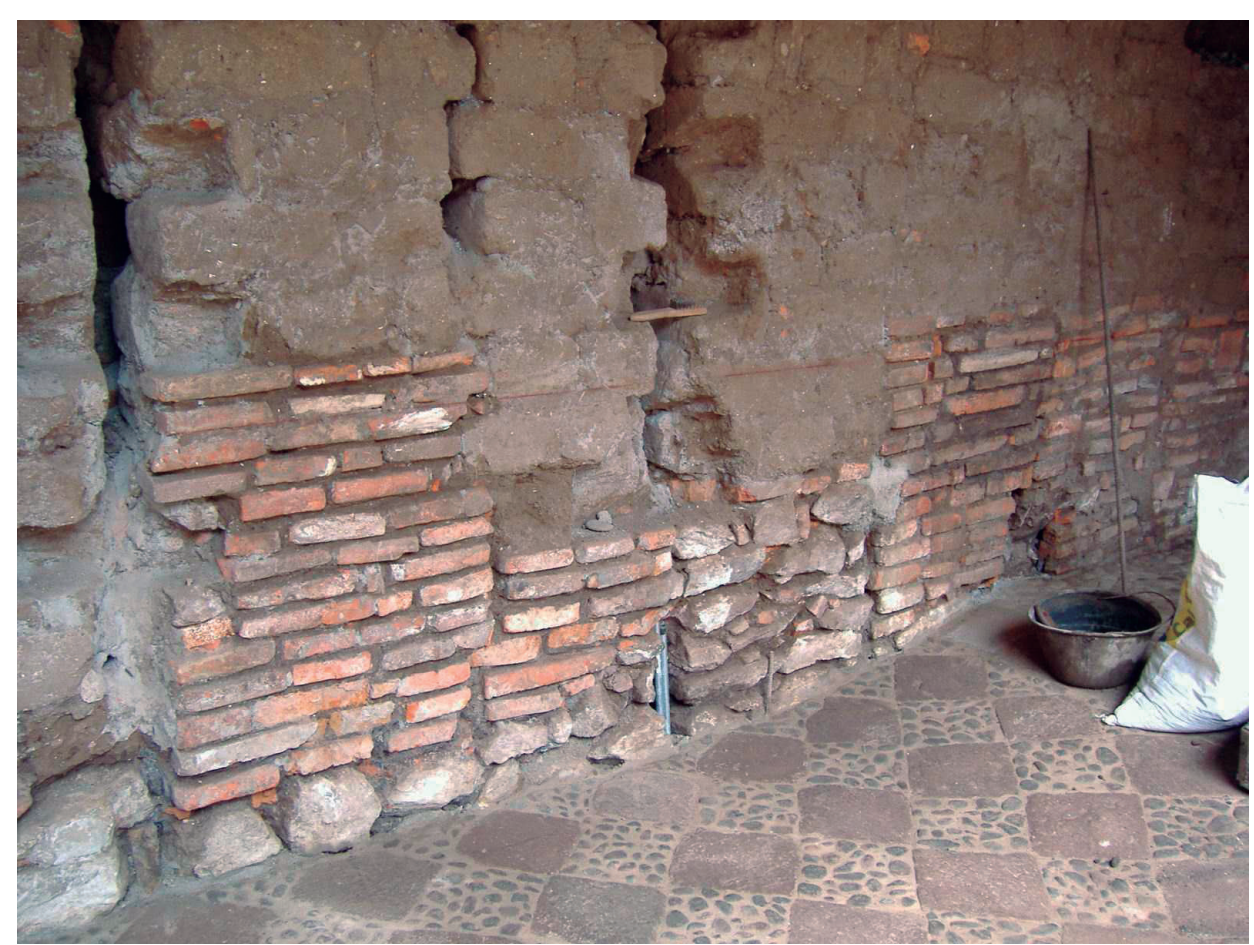

El Archidiácono de la catedral de Nuestra Señora de París (Hugo, 1831) dijo "El libro matará al edificio", preocupado por la aparición de la imprenta, pronosticando un cambio irreversible en la arquitectura medieval como depositaria de las joyas de la escultura, pintura, iluminación y música. El papel remplazaría a la piedra como registro de la humanidad, democratizando su acceso, volviéndolo infinito. John Ruskin vio en Las piedras de Venecia el testimonio vivo de la actividad del hombre de generaciones pasadas, reconociendo en ambos, la piedra y el papel, el mismo valor cultural (Ruskin, 1851). Hoy no se tiene la misma apreciación que Ruskin por los materiales de construcción, porque la aparición del libro obligó a la Arquitectura a tomar otra dirección, pues apareció el arquitecto como profesional cuando se liberaron las superficies de las paredes (Mumford, 1924). De esta manera el maestro mayor de obras se convirtió en un arquitecto que a través de los libros de tratados creó la gramática arquitectónica. Con el libro nacieron Andrea Paladio, Giacomo da Vignola y Sebastiano Serlio; más adelante, con Alberti se estableció que el rol del arquitecto es diseñar y no construir, la idea central de Da Re Aedificatoria (1485).

El libro remplazó a la piedra, pero ¿ha podido remplazar al adobe? Las misiones franciscanas del Camino Real de Alta California parten de la Misión de San Diego de Alcalá, fundada en 1769 en el actual San Diego, hacia el Norte, para terminar en la Misión de San Francisco Solano, fundada en 1823 en Sonoma, años después de la independencia de México. Si se las visita siguiendo un itinerario secuencial, se puede observar el proceso de mutación de las formas originalmente españolas, que al alimentarse de las maneras indígenas se combinan en un lenguaje que no es ya hispano, mudéjar, gótico, ni renacentista italiano, sino uno vital y muy propio, una fusión como la que se produce con un injerto de reproducción vegetativa (Guido, 1925).

El ingeniero Leroy Tolles, junto con los conservadores Edna Kimbro y William Ginell (2002), al estudiar los edificios históricos californianos de tierra, parte de la correlación ruskiana y destaca el rol del adobe como símbolo del carácter de las sociedades iniciales, no solo en la primitiva California, sino en toda América. La afirmación de 
Ángel Guido quizá no sea tan evidente en la arquitectura de Lima y Cuzco, pero está claramente exteriorizada en Arequipa, La Paz y Potosí. Héctor Velarde (1940) le explica graciosamente a Donato Bramante los resultados de la fertilización cruzada de la colisión europeo-indígena mientras caminan juntos por el Centro de Lima; Bramante, orgulloso, le apunta a Velarde sus diseños, que reconoce en las portadas limeñas, pero intrigado le pregunta por qué están pintados de colores, a lo que Velarde responde a un Bramante sorprendido que son así porque no son de piedra, sino están hechos de adobe. Velarde hace uso de historias humorísticas para restaurar la nobleza al adobe. The Adobe (Velarde, 1937) es la historia de Míster Russel, un catedrático londinense de procedimientos constructivos que durante su estadía como invitado en una casa en Barranco descubre que está construida con tierra, sistema que inicialmente consideró una anomalía constructiva, para luego de estudiarlo en más detalle publicar The Adobe, un exitoso libro académico que destaca las propiedades camaleónicas del adobe, cuando junto al yeso, la caña y algo de pintura es capaz de camuflar con todo éxito refinadísimas composiciones clásicas y manieristas. Se trata de una "comedia de materiales", replica Velarde (1937, p. 16), reflexión tan sutil como profunda, porque esta frase conlleva un espectro de significados que van de la Comedia dell'Arte napolitana, callejera y popular, a la dramaturgia de William Shakespeare y Lope de Vega. De ahí que Velarde (1937) concluya que la influencia del adobe en la sociedad limeña "es tan profunda como los profundo de la tierra" (p. 16). Los frágiles ladrillos de adobe de Velarde son culturalmente tan sólidos como las piedras de Ruskin (ver Figura 1). Sin embargo, al final de la historia Míster Bullton, el ofendido anfitrión barranquino justifica el vivir en una casa de adobe por lo limitado de sus recursos económicos; el tiempo le permitirá ahorrar, y mudarse a nueva casa de ladrillo y cemento, la que muy orgulloso fotografía y envía a su amigo en Londres en una tarjeta postal.

La dualidad en la apreciación de la arquitectura de tierra es también parte integral de la cultura peruana, y se puede entender claramente en el World Heritage Inventory of Earthen Architecture ${ }^{1}$ del World Heritage Earthen Architecture Programme (WHEAP) ${ }^{2}$ de UNESCO (Gandreau \& Delboy, 2012), donde de los 150 sitios $^{3}$ hechos total o parcialmente de tierra que se han identificado en la Lista del Patrimonio Mundial, 133 están ubicados en países en vías de desarrollo. El estigma del subdesarrollo hace olvidar fácilmente que la arquitectura virreinal llegó a alcanzar una calidad suficiente para representar complejos elementos arquitectónicos, aptitud que George Kubler (1963) identifica como arquitectura metropolitana, en oposición a la provincial, donde son necesarias avanzadas condiciones de vida urbana para el desarrollo de las profesiones artísticas, un perfeccionamiento que en Lima alcanzó momentum a mediados del siglo XVII (San Cristóbal, 2010). La doble manifestación de la arquitectura virreinal en su independencia creativa dentro de los parámetros del canon europeo y su frágil materialidad recuerda lo débil cuando se compara con el canon que la inspira, situación inconfortable para muchos expertos al llegar el siglo XIX. Teodoro Elmore incluyó el adobe en Lecciones de Arquitectura (1876) bajo la advertencia que "no es un material digno de recomendarse y sus obras serán simples apelmazos de tierra" (p. 36). Elmore coincidía con otros pensadores de la ciudad de su tiempo, como Santiago Basurco, líder del movimiento higienista que durante la última década del siglo XIX, cuando con el apoyo del Gobierno se impulsó la prohibición del uso del adobe (García Bryce, 1980), al parecer con poco éxito, ya que fue necesaria otra prohibición oficial en 1911. A pesar de que las sanciones redujeron su uso, el adobe continuó coexistiendo con otros materiales constructivos, incluso en la misma obra, hasta 1940 (García Bryce,

\footnotetext{
1. Inventario Mundial de Arquitectura Patrimonial de Tierra. Traducción del autor.

2. Programa del Patrimonio Mundial para la Arquitectura de Tierra.

3. Los sitios peruanos incluidos en el inventario son la zona arqueológica de Chan Chan, la ciudad del Cuzco y el Centro Histórico de Lima.
} 
1980) cuando al adobe se le hizo responsable de los extensos daños producidos por el terremoto de Lima del 24 de mayo 1940, de magnitud de momento 8.2 y epicentro frente a las costas del Callao, que afectó el $80 \%$ de las edificaciones de la ciudad.

Richard Neutra, durante su visita el Perú de 1945, dictó la charla El Futuro Metropolitano de una Ciudad con un Gran Patrimonio Histórico ${ }^{4}$. El Arquitecto Peruano cuando cubrió el evento, ignoró el título de la charla por concentrarse en la validación ante Richard Neutra de la Unidad Vecinal Nro. 3 y los planes gubernamentales de vivienda popular (Belaúnde, 1945). De regreso a los Estados Unidos, en su reporte para el Departamento de Estado, Neutra explica que para los limeños el patrimonio monumental es "un obstáculo físico y psicológico" (1945, p. 1) con el que no pueden lidiar racionalmente, por lo que manejan inadecuadamente su preservación e inclusión en la fábrica de la ciudad moderna en progreso. La visión de Neutra no es superficial: reconoce el valor del monumento en su cualidad de pasado y presente, pensamiento que aún no era familiar en el ámbito arquitectónico local. En su reporte Neutra narra su encuentro con Fernando Belaúnde y Víctor Raúl Haya de la Torre, y el paseo guiado que realizó con Emilio Hart-Terré por diferentes partes de la ciudad, incluyendo los Palacios de la Perricholi y de Torre Tagle, el último bastante olvidado desde 1940 y entonces aún a la espera de la necesaria restauración, que finalmente fue realizada en 1955 por Andrés León Boyer Ruiz-Beneyán (Crespo, 2006), quien ya trabajaba en la reconstrucción y restauración de la Catedral del Cuzco financiada por la embajada española luego del terremoto de mayo de 1950. Se podría especular que la doble falta de los limeños ante los ojos de Richard Neutra, en el conocimiento del monumento per se y su rol en la ciudad, se debe a la incomprensión del monumento de tierra, al rechazo que selló el destino del adobe luego del terremoto de 1940 y al incipiente desarrollo de la conservación del patrimonio como especialidad.

Para la sociedad el valor de un monumento es tangible en tres casos: en tanto portador de la memoria colectiva, como registro histórico y como testimonio del ciclo continuo de la vida (Riegl, 1903). Estos valores están arraigados en el pasado y se encuentran en constante conflicto con los valores del presente, que cambian de acuerdo a las modas, gustos, expectativas y la urgencia de la edificación antigua de satisfacer las necesidades habitacionales actuales. Además, el público también impone su deseo colectivo: en el pasado fueron las reconstrucciones idealizadas; la huaca de Puruchuco y la Basílica de Santa María en Cosmedín son claros ejemplos. ${ }^{5}$ Al día de hoy, el acto de preservación debe negociar en compromiso con los valores planteados por Riegl (Lamprakos, 2014), quien sin proponérselo instituyó una atracción a los monumentos que se ha convertido en un culto que ignora las fronteras de las sociedades y las naciones, y ha llenado los vacíos que dejó la religión en la sociedad secular occidental (Aarhenius, 2012). Se trata de un sentimiento similar al de cristalización del amor, que Stendhal explica con la analogía del viaje que realizó desde Bologna, que le causa indiferencia, a Roma, que ve como sinónimo de amor perfecto (1822). Hoy en día el llamado síndrome de Stendhal se utiliza popularmente para explicar el éxtasis que una obra de arte ocasiona en un individuo.

\footnotetext{
4. Richard Neutra visitó el Perú como parte de una gira latinoamericana organizada por el Departamento de Estado norteamericano. El viaje cubrió las ciudades de Lima, Arequipa, Cusco y Puno, y dejó el país rumbo a Bolivia, cruzando el lago Titicaca. La conferencia en mención fue dictada en el local de la Asociación de Artistas Aficionados y traducida por Fernando Belaúnde. Fue cubierta marginalmente por El Arquitecto Peruano de setiembre de 1945. Una fotografía de la conferencia de prensa que llevó a cabo en el Hotel Bolívar se incluye en el libro Richard Neutra: Buildings and projects = Réalisations et projets = Bauten und Projekt, publicado por Neutra y Willy Boesiger en 1951.

5. Puruchuco fue restaurada por Arturo Jiménez Borja en 1959 y la Basílica de Santa María en Cosmedín en 1893-1899 por Giovanni Battista Giovenale, en ambos casos sobre la base de hipótesis. Sin embargo, las partes nuevas fueron diferenciadas (Jiménez Borja, 1988; Jokilehto, 2004) de acuerdo a los principios de Camilo Boito publicados en 1883.
} 


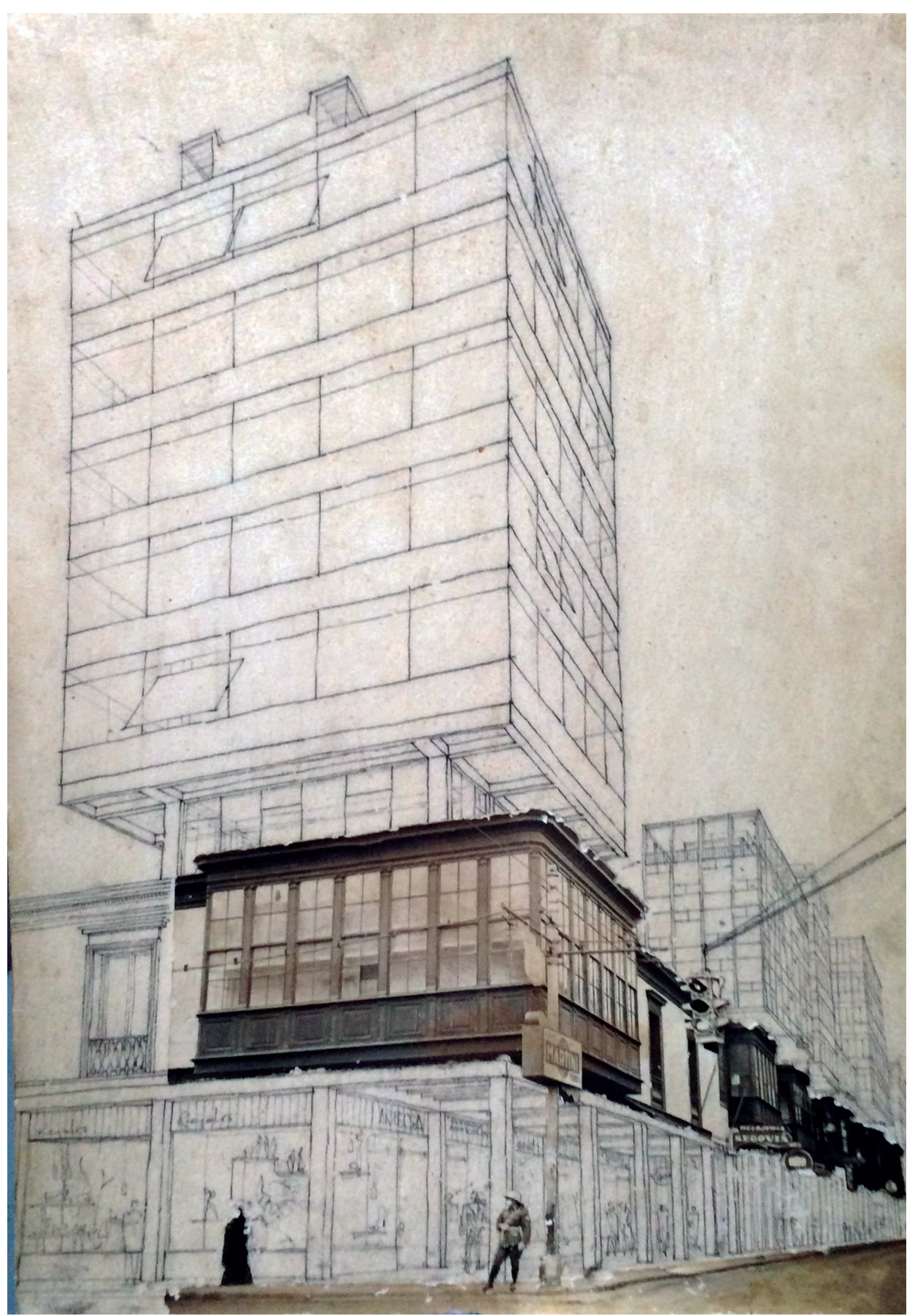

El cambio en la percepción de los monumentos a través del tiempo es indiscutible al notar que hoy resulta escandalosa leer la historia de Bruno Rosselli, ficcionalizada por Mario Vargas Llosa, su alumno de historia del arte en la Universidad Nacional de San Marcos, en la obra de teatro El Loco de los Balcones (1993). Rosselli había llegado a Lima autoexiliado durante la Segunda Guerra Mundial, como tantos otros profesionales italianos, luego de una larga temporada como profesor del Vassar College de Nueva York (PB, 2013). En Lima Roselli dejó la política y se enfrascó en la batalla, mucho más quijotesca, de abrir los ojos de los limeños ante la belleza única de su patrimonio construido.
Figura 2. Fotomontaje de la exposición de José García Bryce y Gianfelice Fogliani en diciembre de 1956, Lima, 2014. Archivo fotográfico de la obra. 


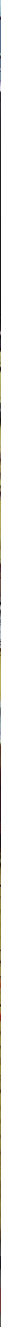

Figura 3. Parte desplomada al interior del Hotel Comercio, declarado monumento de la nación el 23 de julio de 1980, 2014. Archivo fotográfico de Héctor Abarca.

Figura 4. Fachada ya desaparecida en el Jirón Lampa 245 (siglo XIX). Una de las tantas edificaciones demolidas poco a poco para ser convertida en aparcamiento público informal, practica común ya criticada desde los años 60, Lima, 2014. Archivo fotográfico de Héctor Abarca.
El diario Última Hora, por su interés en las crónicas urbanas y pintorescas que entretuviesen a sus lectores, fue el medio que mejor ha retratado esta aventura. Algunas veces sus bromas no eran percibidas como tales, como la crónica sobre la entrevista que la revista Time hizo a Roselli ${ }^{6}$, que resume burlonamente en la frase "según los gringos los limeños ni siquiera somos capaces de darnos cuenta del valor artístico ni de la fama histórica de nuestros balcones como para querer salvarlos" ("Roselli", 1959, s/n). Una reflexión dura que describe a la sociedad limeña de un plumazo: las charlas, visitas, plantones y piquetes organizados por Roselli no fueron suficientes para calar en la insensibilidad limeña. Vargas Llosa (1993) utilizó esta absurda tara de la idiosincrasia limeña para hacer un estudio artístico y moral del balcón limeño, y recordar que es imposible construir un futuro si no se tiene un pasado. Aldo Brunelli, el soñador alter ego vargasllosiano, no puede cerrar sus ojos ante la degradación de la ciudad y en un auto de fe decide inmolarse ahorcándose junto a una pira hecha con todos los balcones que había rescatado; sin embargo, no consigue acabar con su vida porque el madero apolillado del que se había colgado se quiebra al recibir su peso. Fue un balcón agradecido quien le ha salvado la vida, dice Varga Llosa, en reacción a lo irracional que es el suicidio como acto desesperado de protesta, para que siga adelante con su ya no tan fútil tarea pedagógica. La ficción de Vargas Llosa no es muy distinta de la realidad: en 1959 Roselli decidió quemar un balcón que había comprado por 750 soles como acto

6. El número de la revista Time al que hace referencia Última Hora es la edición americana del 20 de julio de 1959. He revisado la colección de la revista Time de la Biblioteca Pública de Vancouver y no he encontrado referencia a Roselli en ninguno de los ejemplares publicados entre mayo y octubre de 1959. Los índices de 1950 y 1960 tampoco señalan entradas sobre la entrevista a Roselli bajo los nombres architecture, Lima, Perú, Roselli. Es posible en lugar de Time se halla querido hacer referencia a la revista Life, otra revista de la misma casa editorial que coincidentemente tiene una edición con la misma fecha -20 de julio de 1959-, pero ni este número ni otros cercanos hacen referencia a Roselli. Aún queda por revisar Life en Español, que se publicó entre 1952 y 1969. 
de protesta. Sus Ilamas, afirmó Sebastián Salazar Bondy, "darán luz sobre un fenómeno que solo en la perspectiva histórica se revelará en su monstruosa magnitud" (1958a, p. 10). Salazar Bondy (1958b) apelaba a salvar la tradición no del progreso sino de la incultura; esta era la batalla en 1958 y tristemente aún es la actual.

Los arquitectos peruanos como gremio profesional tienen una posición clara respecto a la protección de Lima y sus monumentos. Basta recordar el momento del ensanche de los jirones Arequipa, Cuzco, Camaná y Lampa, que se ejecutó para facilitar el flujo vehicular por el centro de Lima, atosigado de "rascacielitos", como los llamaba sarcásticamente Roselli (Salazar Bondy, 1958b) al imaginarlos frente a los edificios de Nueva York. En 1966 Caretas $^{7}$ reconocía en Lima a una de las pocas ciudades históricas con un reglamento tan permisible que había hecho que los rincones de la ciudad dejen de producir postales tan pintorescas como las que circulaban del Barrio Chino de San Francisco, el Barrio Criollo de Nueva Orleans o el centro de San Agustín en Florida ("Lima S.O.S.", 1966, 29 de abril). ¿Qué hacer? Caretas escucha atentamente la sugerencia de Roselli de dejar los balcones adelante y permitir rascacielitos detrás, idea que es muy probable que haya tomado de la exposición que José García Bryce y Gianfelice Fogliani realizaron en diciembre de $1956^{8}$, donde presentaron una interesante y controvertida idea para salvar los históricos balcones limeños que contemplaba conservar la fachada de dos pisos y la escala de las casas, uniéndolos a edificios de cristal que se elevaban pocos metros detrás (ver Figura 2). Desde la Municipalidad, Benjamín Doig se empecina en abrir la ciudad, desoyendo a sus colegas y sus alternativas mientras Pimentel lista las obras ya desaparecidas y cercenadas en 1966: el Convento de Santa Teresa, el ábside de la Iglesia de la Concepción y un buen trozo del convento de San Francisco. No obstante, los ensanches continuaron por más de una década, hasta terminar en 1971 con la Casa Beltrán, frente a la Plazuela de San Marcelo, a pesar de la oposición pública.

Existen casos similares a nivel internacional, como la desaparición en 1963 de la Estación de Pensilvania en Nueva York, construida en 1910 por los arquitectos neorrenacentistas McKim, Mead y White, que ocupaba dos manzanas en el midtown de Manhattan. Las protestas, pancarta en mano, de Jane Jacobs, Philip Johnson y Aline Saarinen poco hicieron para evitar su demolición cuando el Ferrocarril de Pensilvania decidió vender los aires para el futuro Madison Square Garden (1968), del reconocido modernista Charles Luckman a cambio de la construcción gratuita de una estación subterránea. Fue un gran negocio inmobiliario y un atentado contra el patrimonio reciente que llevó a la creación de la New York City Landmarks Preservation Commission en 1965 (Golderberg, 1990), el mismo año en que se fundó el World Monument Fund (WMF). Estas instituciones siguen llevando adelante el delicado y arduo trabajado de establecer y dirigir los programas de concienciación, y las políticas de protección del patrimonio que sirven de modelo a instituciones similares constituidas en otros países y ciudades. A la fecha son muchas las obras que a pesar de tener un estatus de monumento declarado han desaparecido (ver Figura 3). Una de ellas fue la Iglesia de la Compañía de Jesús en Pisco, edificada entre 1689 y 1729, que colapsó durante el terremoto de agosto del 2007, sus restos demolidos y rápidamente desechados..$^{9}$ Otro caso

\footnotetext{
7. Entrevista a Víctor Pimentel y Benjamín Doig con motivo de la revisión que la Cámara de Diputados estaba dando a la Ley de Defensa del Patrimonio Monumental de la Nación de 1966, escrita por Pimentel. Publicada en Caretas, n 329 del 29 de abril 1966.

8. La exposición se llevó a cabo en una galería del centro de Lima. Una imagen de la propuesta se publicó en la revista Caretas, n 123, del 2-16 de diciembre de 1956.

9. El Ministerio de Cultura realizó una evaluación rápida de los efectos del terremoto de Pisco, que fue publicada en La Gaceta Cultural del Perú, n²9, de 2007, notando que los escombros de la Iglesia de la Compañía fueron rápidamente retirados, con lo que desaparecieron piezas arquitectónicas, litúrgicas y obras de arte, si bien muy dañadas aún con mucho valor histórico y artístico.
} 
Figura 5. HABS guidelines recording historic structures and sites with HABS measured drawings, 2008.

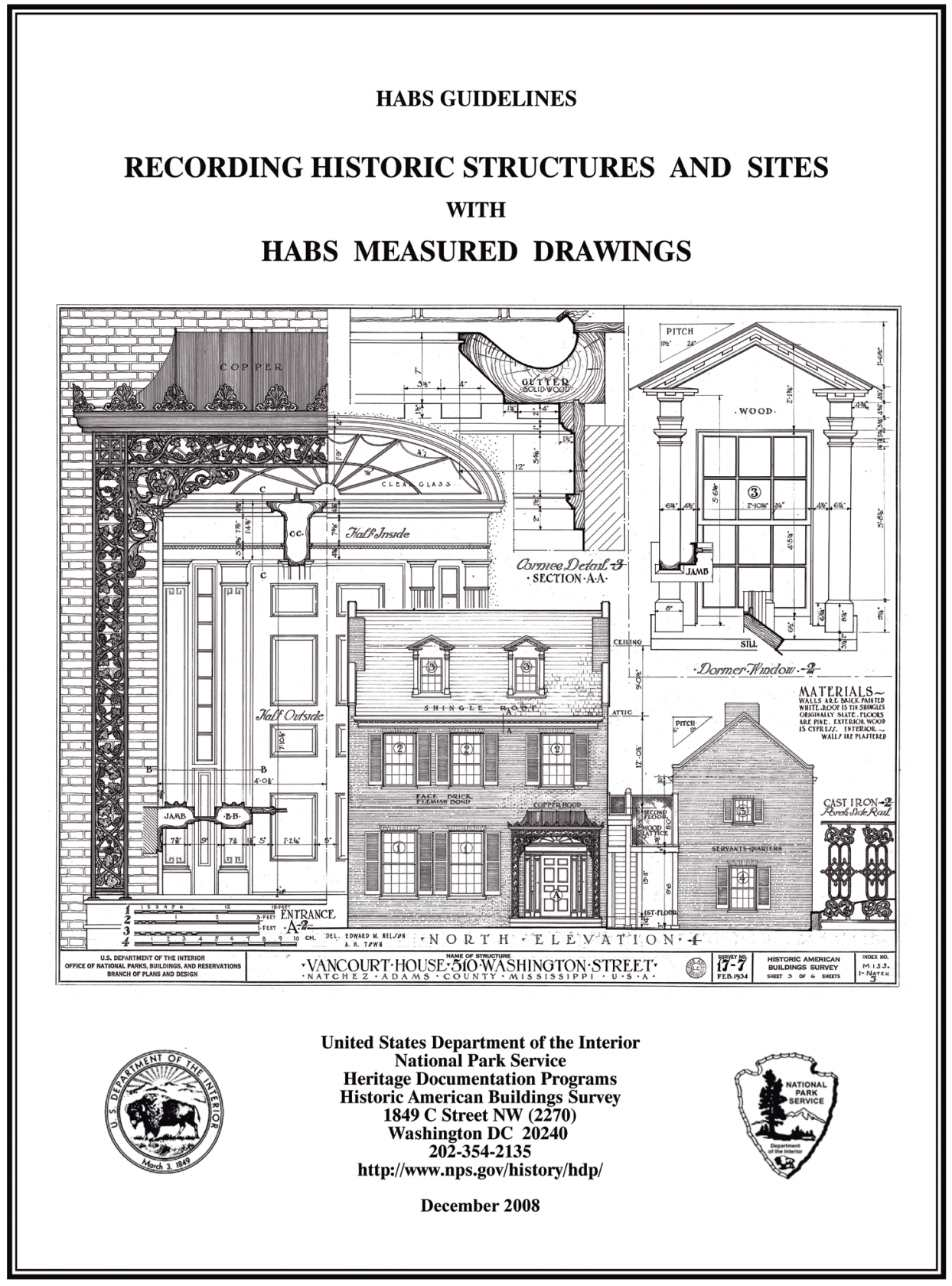

es la casona ubicada en el Jr. Huallaga 731-745, que fue demolida utilizando artimañas judiciales (Lizarzaburu, 2014)..$^{10}$

Resulta desesperanzador ver como hoy lucen abandonados uno de los edificios que Víctor Larco Herrera comisionó en 1924 a Richard Malachowsky en la Plaza Dos de Mayo y el edificio El Buque (s. XIX), en la esquina de los jirones Cangallo y Junín, luego de los incendios del 2002 y 2016 . Estas pérdidas son un golpe a la memoria colecti-

10. Se debe tener claro que la demolición en realidad no fue producto de la Ley 30230 de estímulo a la inversión privada, a pesar de que así se sugirió. 
va social y a la identidad del lugar, entendida como la relación del individuo con el pasado histórico y el reciente. De acuerdo con Riegl, la importancia de El Buque en la historia del desarrollo de la música criolla peruana lo hace un monumento actual, no uno del pasado, y parte de la consciencia de la posteridad. ${ }^{11}$ La indiferencia de la ciudadanía se da porque los arquitectos e historiadores del arte, y la arquitectura han fallado en comunicar, compartir y poner en consulta su trabajo; el lamento de hoy y el debate reflejado en Caretas, de 1966, son percibidos como discusiones entre arquitectos (ver Figuras 4). El error parte de las aulas, donde la educación se había regido bajo el modelo del gran arquitecto / artista / prima donna que celebra a figuras como Louis Sullivan, Frank Lloyd Wright, Philip Johnson y Louis I. Kahn, quienes tenían dificultad de aceptar colaboraciones y someter su ideas al debate; como educadores le hicieron un deservicio a sus estudiantes, convirtiéndolos en personas arrogantes (Saint, 1983). Basta revisar cualquier texto de Wright para leer cuan orgulloso estaba de la peculiaridad de que su trabajo fuese de una individualidad inmaculada (Wright, 1914).

Al llegar la década de 1960, la crisis del movimiento moderno trajo a nuevos pensadores de la ciudad: Kevin Lynch, Jane Jacobs, Gordon Cullen, Aldo Rossi, Cristopher Alexander y Christian Norberg-Schulz, quienes renegaron del individualismo y entendieron la conservación del patrimonio por las relaciones que tienen los conjuntos monumentales con la fábrica de la ciudad histórica (Corten, Geurts, Meurs \& Vermeulen, 2014). Gustavo Giovannoni, cuyas ideas primordiales estructuraron la Carta de Atenas de 1931 (Hernández, 2013), ya desde 1925 hacía incidencia en la correlación recíproca entre el monumento y su entorno, viéndose ambos de afuera hacia adentro y viceversa. La Declaración de Ámsterdam sobre el Patrimonio reafirma este pensamiento y empodera al pueblo europeo a tomar la responsabilidad colectiva de proteger el patrimonio monumental, colocando a la conservación arquitectónica no como un ítem marginal, sino como un objetivo primordial del planeamiento urbano y rural (Consejo de Europa, 1975). Las prácticas recientes de planificación territorial piden dejar de ver la ciudad como una estructura física y se acercan a la escuela del landscape urbanism ${ }^{12}$, que considera a la ciudad una continuidad de interconexiones inmateriales que fluyen entre presente y pasado, haciendo borrosa la diferenciación entre objetos arquitectónicos y estructuras urbanas, y entre las áreas de conservación y las de desarrollo (Corten et. al., 2014). Promueve la integración de las estrategias de conservación del patrimonio en los programas nacionales de desarrollo, combinando para ello los objetivos de la conservación del patrimonio con los de desarrollo social y económico (UNESCO, 2011). UNESCO apuesta por expandir el entendimiento del monumento en su rol de mejorador de la calidad de vida y el medio urbano, incluyendo la participación ciudadana junto a las usuales herramientas normativas, financieras, técnicas y de gestión.

Jean-Paul Corten, experto en estrategias de patrimonio urbano del Institute for Housing Studies ${ }^{13}$ de la Universidad Erasmo de Róterdam, es claro al indicar que las cartas de UNESCO, como la Carta de Venecia, ya han alcanzado sus objetivos al lograr que sus

\footnotetext{
11. Se trata del valor rememorativo intencionado y del valor de contemporaneidad de Alois Riegl (González-Varas, 2008).

12. Landscape urbanism no tiene una traducción exacta al español. Se le llama indistintamente urbanismo y paisaje o urbanismo del paisaje.

13. El Institue for Housing Studies surgió como evolución del Bouwcentrum International Education, instituido en 1958 para transferir a países en vías de desarrollo el conocimiento y la experiencia adquirida por Roterrdam durante la reconstrucción después de la Segunda Guerra Mundial. A finales de los años 70 desarrolló estudios sobre la casas-huerta de Surquillo junto a Manuel Llanos John, miembro de uno de los tres equipos ganadores de la sección peruana del concurso PREVI (1968) junto a Elsa Mazzarri con el proyecto P-22, y ganador del Hexágono de Oro en la tercera Bienal del Perú (1978) por el edifico del Banco Central de Reserva del Perú. Manuel Llanos habló de las experiencia de las casas huerta en la conferencia Latin American Incrementalism: From PREVI to the Present organizada por el Museo de Arte Moderno de Nueva York (MoMA) y The Architectural League New York el 25 de abril de 2015.
} 
miembros adopten leyes que protegen el patrimonio. Ahora es el patrimonio el que enfrenta la presión social y financiera de servir activamente a la ciudad, una urgencia realmente palpable en las ciudades en vías de desarrollo donde la ausencia o los límites en el acceso al financiamiento hacen de la inversión pública en conservación un acto insostenible en el largo plazo. Por ello, desde 2005 el Consejo de Europa, a través de la Declaración de Faro para el Desarrollo del Diálogo Intercultural, está revisando las políticas europeas para hacer uso de las potencialidades de los valores patrimoniales, que como se ha observado son variables y adaptables en el tiempo, para entender a la gestión del patrimonio como una actividad dinámica que reconoce y maneja al cambio como elemento inherente (Corten et. al., 2014).

¿Cómo se puede repensar los monumentos hacia este nuevo objetivo si el Perú aún no ha sido capaz de consolidar la profesión del conservador, establecer la estandarización del registro y documentación monumental, y normar la redacción del proyecto de restauración?

\section{La información patrimonial}

La Carta de Venecia (1964) establece que los encargados del cuidado del entorno histórico son los responsables de la elaboración de una documentación patrimonial precisa. Esta tarea que debe incluir todas las fases del trabajo de intervención: desmontaje, consolidación, recomposición e integración del monumento, información que posteriormente deberá ser compilada y puesta a disposición en un archivo público (Consejo Internacional de Monumentos y Sitios [ICOMOS], 1964). En 1996 en Sofía se revisitó este punto, y se estableció que los registros documentales son un compromiso nacional y una cuestión prioritaria. Su información debe ser homologada, exacta y sobre todo pública, porque son documentos valiosos para la gestión de riesgos en caso de una perdida inesperada del patrimonio cultural (ICOMOS, 1996).

Uno de los casos más interesantes sobre el establecimiento, desarrollo e institucionalización de los archivos documentales se dio en los Estados Unidos mucho antes del establecimiento de ICOMOS en 1965 como resultado de la Carta de Venecia. En 1933 se creó el Historic American Buildings Survey $(\mathrm{HABS})^{14}$ (ver Figura 5). Uno de los objetivos primordiales del HABS fue dar trabajo a los arquitectos, topógrafos y fotógrafos desocupados durante la Gran Depresión de 1929 (HABS, 2008a), quienes tenían la formación necesaria para inventariar las edificaciones que la rápida urbanización de las ciudades norteamericanas estaba haciendo desparecer. El proyecto dio prioridad a los edificios que podrían perderse inmediatamente y aun hoy ejecuta acciones de carácter urgente para el registro de edificaciones cuya demolición es inminente. Desde un inicio se establecieron estándares para las tres categorías de registro de las tareas de levantamiento: dibujo, historia y fotografía. Dependiendo de la importancia del bien los criterios de documentación responden a cuatro niveles de rigurosidad respecto al contenido de la información, yendo desde una planimetría esquemática acompañada de fichas arquitectónicas, a elaborados planos acotados unidos a un estudio histórico que va acompañado de fotografías exteriores e interiores de gran formato. Los planos tienen dos tamaños (19"x24" y 24"x36") e incluyen detalles de los elementos que definen el carácter estilístico de la edificación (National Parks Service, 2008), lo que en inglés se llama character defining elements, y en italiano particolare architettonico. Las fotografías tienen tres formatos $\left(4^{\prime \prime} \times 5^{\prime \prime}, 5^{\prime \prime} \times 7^{\prime \prime}, 8 " x 10^{\prime \prime}\right)$, y documentan texturas, relacio-

\footnotetext{
14. Uno de los objetivos primordiales del HABS fue dar trabajo a los arquitectos, topógrafos y fotógrafos desocupados durante la Gran Depresión (HABS, 2008a). Posteriormente el programa se especializó, y se creó además el Historic American Engineering Record o Registro de Ingeniería Histórica de Estados Unidos (HAER) y el Historic American Landscapes Survey o Registro de los Paisajes Históricos de Estados Unidos HALS). Cada año se realiza una competencia para premiar al mejor set de planos y al mejor plano individual como incentivo para preparar al siguiente generación de conservadores (NPS, s.f.).
} 


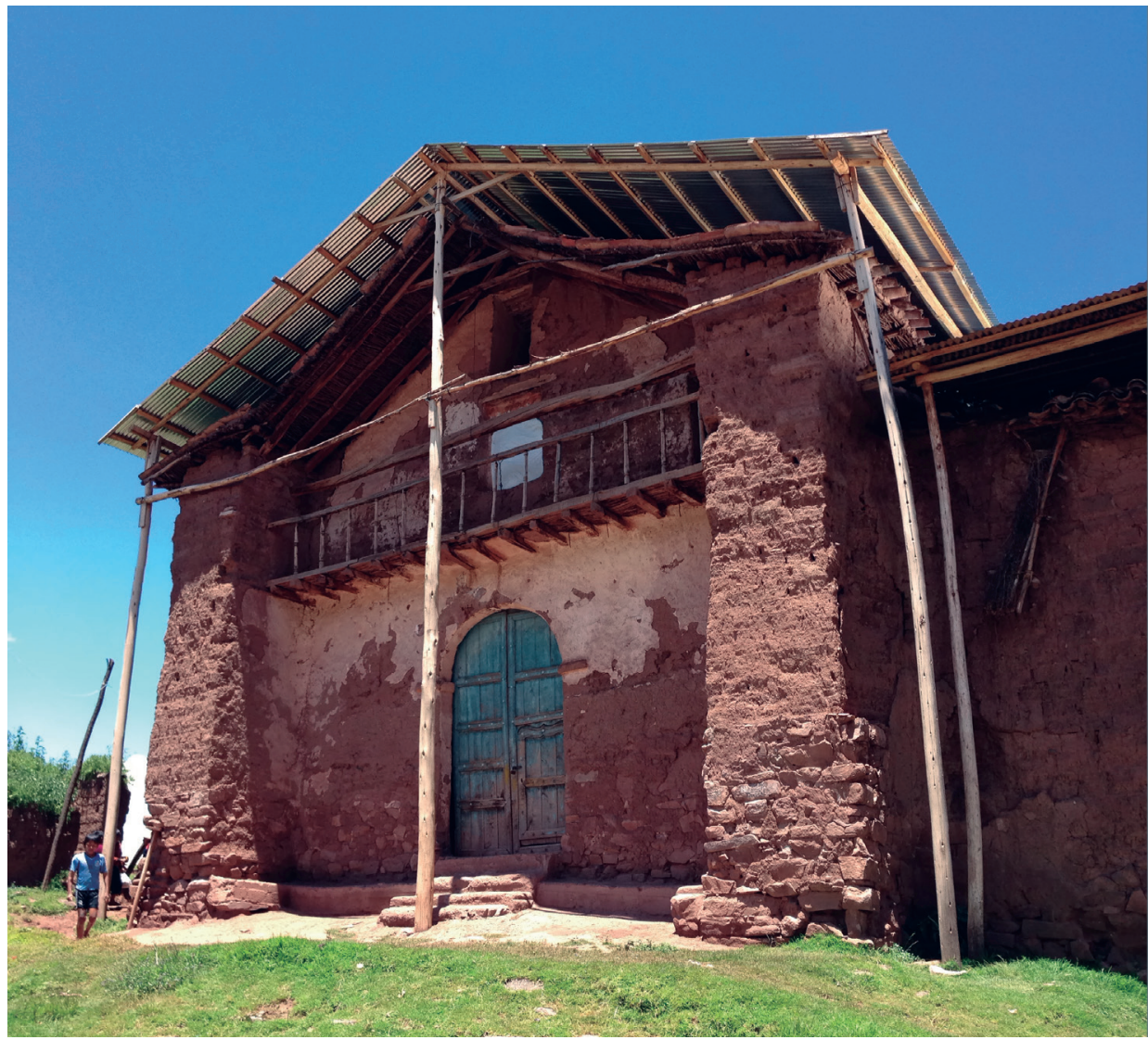

nes espaciales y detalles que no son fáciles de representar planimétricamente (Heritage Documentation Programs, 2015). El reporte histórico debe indicar el significado de la edificación, las razones que llevaron a su ejecución, el contexto histórico, la descripción de la construcción y de sus interiores; como anexo, se incluyen todas las notas de campo (HABS, s.f.). El material producido presta igual atención a la calidad gráfica como a la certidumbre de la información, que debe ser verificable y de fuente cierta. La base de datos HABS no es un listado de monumentos protegidos sino un registro de documentación y catalogación que servirá para futuros estudios, y en algunas ocasiones como herramienta para nominar un edificio como patrimonio condal, estatal o nacional. Su información es pública y está disponible en línea. ${ }^{15}$

Historic Buildings and Monuments Commission for England, popularmente como Historic England ${ }^{16}$ no ofrece un paquete de instrucciones detalladas, pero su guía instructiva Understanding Historic Buildings: A Guide to Good Recording Practice ${ }^{17}$ explica de manera simple las características de un levantamiento acertado, un buen levantamiento, y las razones por las que se debe llevar a cabo. Por ejemplo, es posible en algunos casos prescindir del desarrollo de las elevaciones si el edifico es sencillo y las fotografías muestran el detalle necesario.

\footnotetext{
15. Todas las entradas de los programas HABS, HAER y HALS están disponibles a través de la página web de la Biblioteca del Congreso de los Estados Unidos: http://www.loc.gov/pictures/collection/hh/.

16. Historic England es el organismo del Gobierno Británico encargado de registrar y proteger los ambientes históricos de Inglaterra, y es el asesor oficial ante el gobierno central y local en temas patrimoniales.

17. Comprendiendo los edificios históricos: Una guía para la práctica de un buen registro. Traducción del autor.
}

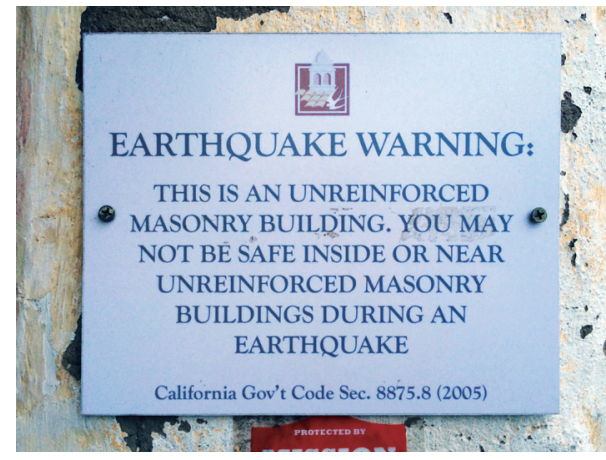

Figura 6. Iglesia de Santiago Apóstol de Kuño Tambo (siglo XVI). Edificación tipológica seleccionada por el Proyecto de Estabilización Sismorresistente del Instituto de Conservación Getty, Kuño Tambo, 2014. Archivo fotográfico de Héctor Abarca.

Figura 7. Advertencia en caso de terremoto. Misión de San Carlo Borromeo del Carmelo (1771). Carmel by the Sea, 2015. Archivo fotográfico de Héctor Abarca. 


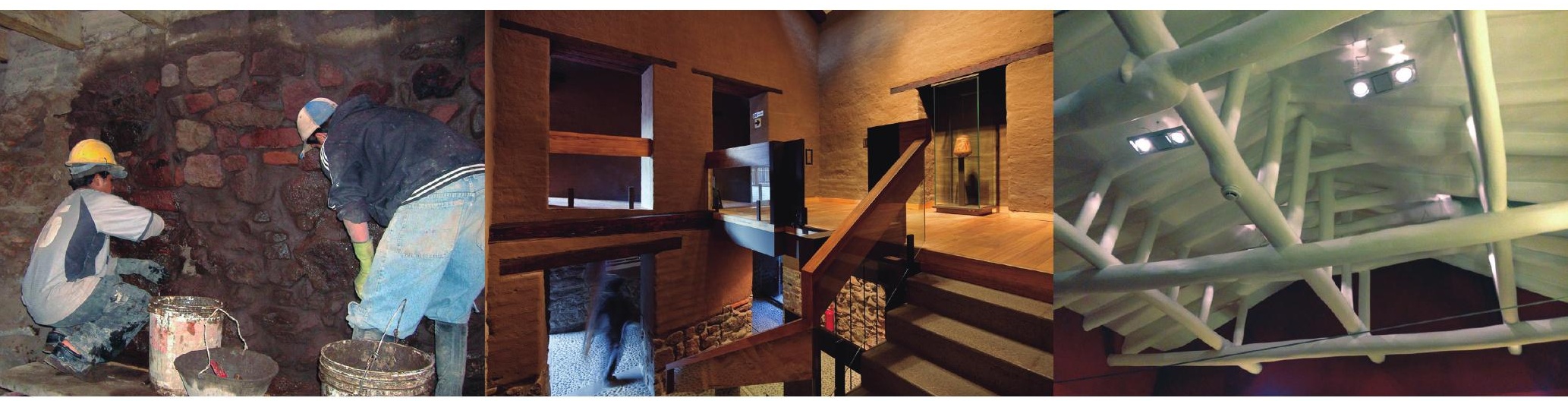

Figura 8. Solaqueo con barro de un muro de piedra. Restauración de una Casa del Alabado (s. XVII), Quito, 2006. Fotografía por Héctor Abarca.

Figura 9. Restauración de una Casa del Alabado (s. XVII). López López Arquitectos (2006). Fotografía por Sebastián Crespo.

Figura 10. Armadura de Par y nudillo del Restaurante El Limo, Cuzco, 2014. Fotografía por Héctor Abarca.
En el caso de obras patrimoniales de mayor orden, el levantamiento está reglamentado por el manual Metric Survey Specifications for Cultural Heritage ${ }^{18}$ (Andrews, Bedford \& Bryan, 2015), que incluye provisiones sobre seguridad en obra, la responsabilidad sobre daños producidos durante la campaña de trabajo y los derechos de autor del material producido. Otros documentos, como The Presentation of Historic Building Survey in $C A D^{19}$ (Andrews, Blake, Fradgley, \& Roberts, 2005) y 3D Laser Scanning for Herita$g e^{20}$ (English Heritage, 2011), regulan es uso de herramientas digitales como el CAD, el GPS, la fotografía rectificada, la ortofotografía, la fotogrametría, el escáner laser, y las estaciones totales. Los dibujos en CAD se producen para ser impresos a escala métrica 1:100, 1:50 y 1:20, e incluyen diagramas constructivos; los detalles ornamentales se dibujan a escala 1:1 y deben complementarse con bocetos a mano alzada cuando las fotografías son incapaces de mostrar la profundidad de las superficies.

En el Perú, a falta de normas locales para el registro y levantamiento, las mayores agencias de conservación han desarrollado sus propios estándares adaptándolos de sus países de origen a los usos y costumbres locales. Esta desorganización es una barrera que ralentiza la diseminación de la información patrimonial, que se entiende como las actividades integradas de registro documentación, gestión de la información, ${ }^{21}$ y afecta la eficiente colaboración entre profesionales y la formación de nuevos conservadores.

Para el levantamiento interior de los elementos constructivos y de la pintura mural de la Iglesia rural de Kuño Tambo, en la provincia de Acomayo (ver Figura 6), el laboratorio Immersive Media Studio de la Universidad de Carleton (CIMS) escogió la fotogrametría como sistema de registro, por ser una tecnología de fácil acceso (Percy et. al., 2013). Para ello desarrolló una metodología sencilla para ser usada en edificios de tierra, que no solo es de aplicación nacional sino global (Granda et. al., 2014). Los trabajos de fotogrametría forman parte del Seismic Retrofitting Project (SRP) ${ }^{22}$ que está realizando el Instituto de Conservación Getty (GCl) con la Universidad de Minho en Portugal, la Universidad Católica del Perú (PUCP) y el Ministerio de Cultura del Perú23. En este

\footnotetext{
18. Especificaciones de levantamiento acotado para el patrimonio cultural. Traducción del autor.

19. La presentación del levantamiento del edificio histórico en CAD. Traducción del autor.

20. Escaneo láser 3D para el patrimonio. Traducción del autor.

21. Más información respecto a la gestión de la información patrimonial o heritage information se puede encontrar en Letellier, R., LeBlanc, F. \& Schmid, W. (2007). Recording, documentation, and information management for the conservation of heritage places: guiding principles. Los Ángeles: Getty Conservation Institute.

22. El nombre oficial del proyecto en español es: Proyecto de Estabilización Sismo Resistente.

23. Para mayor información sobre el proyecto Seismic Retrofitting Project del Getty Conservation Institute, consultar http://www.getty.edu/conservation/our_projects/field_projects/seismic/.
} 
caso el registro fotogramétrico es parte del proyecto de conservación que han desarrollado los arquitectos de la Dirección Desconcentrada de Cultura del Cusco, pero es importante extender su uso como herramienta de registro documental. El conservador inglés Bernard Feilden (1997) recomienda que el levantamiento fotogramétrico sea parte del protocolo de documentación de monumentos en zonas sísmicas, ya que permite realizar de forma rápida y desde una distancia segura el registro rápido ${ }^{24}$ que debe de hacerse inmediatamente después de un terremoto para identificar las áreas vulnerables que podrían perderse definitivamente (ver Figura 7).

En el Perú se le llama expediente técnico de obra al conjunto de documentos que permiten la ejecución correcta de una obra, en España estos documentos reciben el nombre de proyecto de ejecución, y en los Estados Unidos y Canadá se les conoce como contract documents. En todos los casos están compuestos por un juego de planos acotados y especificaciones técnicas, y se siguen entendiendo como parte de un trámite cuyo único objetivo es el obtener una licencia de construcción, financiamiento, ser incluido en algún programa de desarrollo gubernamental, o solicitar ayuda a la cooperación internacional. Si se revisan algunos expedientes de proyectos públicos de restauración producidos en los últimos años no es raro encontrar que están incompletos, y se repiten o toman prestadas especificaciones y detalles de proyectos anteriores, que muchas veces no son aplicables. En el pasado esta práctica informal funcionó (Hayakawa, 2010). José Hayakawa, en Restauración en Lima: Pasos y Contrapasos (2010), expone una constante en su estudio, que cubre 70 años, desde 1920 a 1990, de la historia del proyecto de conservación y restauración limeño: los expedientes técnicos siempre han presentado diseños estructurales muy básicos o incompletos, que al final se resolvieron satisfactoriamente sobre la marcha. No obstante, en la actualidad no se puede dejar al azar la toma de todas las decisiones técnicas y morales del proyecto. La redacción del proyecto debe responder con certeza ante los requisitos, controles y expectativas más complejas; durante su ejecución un expediente pobre produce incertidumbre, además de los consabidos sobrecostos producto de las partidas ignoradas, y no menos onerosos son los peligros de dejar decisiones importantes a la discreción del contratista. Está probado que el secretismo en los proyectos y sus presupuestos abren una ventana a la corrupción. La trasparencia y al escrutinio público fomentan la competitividad entre los profesionales y las empresas que participan en las licitaciones. Como se verá a continuación, en el caso de Quito, la práctica profesional de la conservación y restauración avanza cuando está expuesta a la crítica y la discusión.

En Quito todos los proyectos de restauración están disponibles como material de referencia en la biblioteca del antiguo Fondo de Salvamento (FONSAL), hoy Instituto Metropolitano del Patrimonio de Quito (IMP). El fácil acceso a tan vasto catálogo de proyectos ha despertado una sana competencia entre los arquitectos, que se ha reflejado en el aumento de la calidad de la redacción de los nuevos proyectos al saber que pueden consultar, reproducir y adaptar el detalle constructivo que necesiten para su proyecto, y posteriormente contribuir al engrosamiento de la colección con su propio trabajo (FONSAL, comunicación personal, marzo 2006) (ver Figuras 8 y 9). Para poder trabajar en el Centro Histórico de Quito como jefe de proyecto o arquitecto de registro, un arquitecto debe de haber participado previamente en dos proyectos como asistente o asociado (Vinueza, J., comunicación personal, 30 de marzo 2006).

Esta práctica garantiza un grado de experiencia antes de enfrentar individualmente un proyecto más complejo. En California sucede algo similar, el California Historical Building Code (2016) o Código de Edificación Histórica del Estado de California ha

24. El registro rápido o rapid assessment es un método de levantamiento de información patrimonial realizado de manera expeditiva, en grupos, que tiene como objetivo comprender el comportamiento de la edificación, discutir la extensión de las fallas encontradas y sus posibles causas, e identificar los daños ocasionadas por el desastre natural, así como los preexistentes.

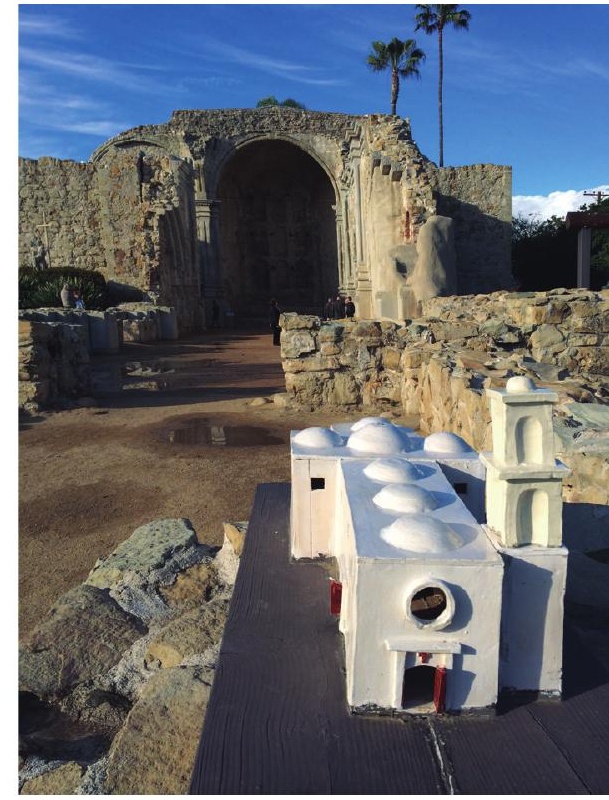

Figura 11. Las ruinas de la Gran Iglesia de Piedra (1797-1806) de la Misión de San Juan Capistrano junto a una maqueta que explica su configuración antes de su colapso luego de un terremoto en 1812. Fotografía por Héctor Abarca, 2015.

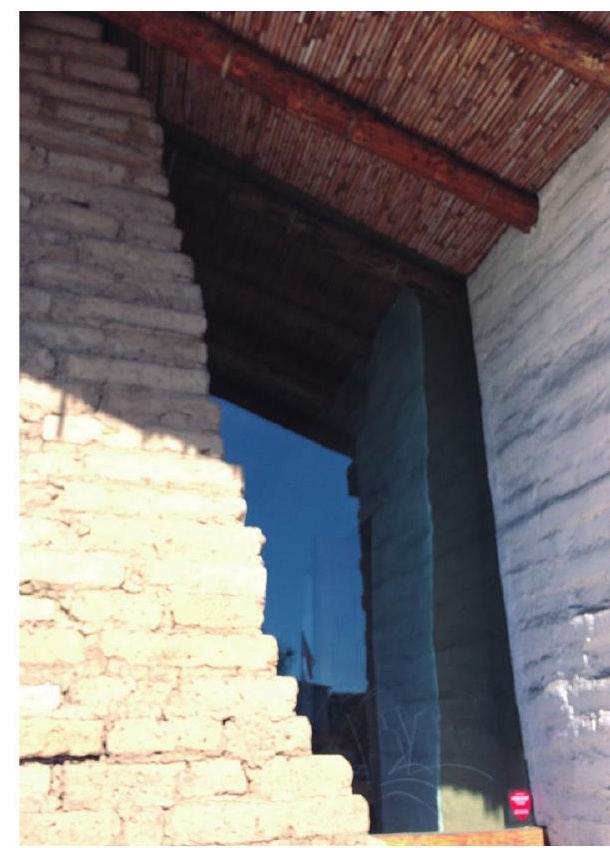

Figura 12. Cerramiento con cristal templado en un muro de adobe que se decidió dejar incompleto en la restauración del Real Presidio de Santa Bárbara del 2006. Fotografía por Héctor Abarca, 2015. 


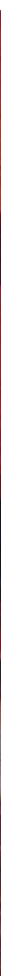

Figura 13. Iglesia de la Compañía de Jesús en Quito (1725) a pocos meses de la reapertura en diciembre el 2005 luego de 12 años de trabajo y dos incendios. Fotografía por Héctor Abarca.

Figura 14. Coro alto de madera de la Catedral de San Carlo Borromeo. Los arquitectos basaron su selección de colores y diseños decorativos en la paleta de color original pero no los repitieron integralmente. El proyecto incluye un nuevo sistema de aire acondicionado, Monterey, 2015. Fotografía por Héctor Abarca. creado provisiones que únicamente pueden ser aplicadas por arquitectos e ingenieros expertos en edificaciones históricas, como establecer una solución equivalente que brinde un rango aceptable de seguridad, dado que es muy difícil requerir a la edificación histórica un comportamiento contemporáneo (California Building Standards Comission, 2016). Con estas políticas ambas jurisdicciones han garantizado un envidiable mejoramiento en la capacidad técnica de sus conservadores, un círculo virtuoso y sostenible donde todos son ganadores.

El rol del expediente técnico es fundamental como futuro registro, testimonio y control, en especial de actividades cuya práctica está declinando. Puede tomarse como ejemplo la armadura de par y nudillo, que en muchas regiones del Perú es una práctica viva (ver Figura 10). Si se incluyen detalles de su fabricación en el expediente, durante la ejecución es probable que el carpintero, confiado en su larga experiencia, ignore las instrucciones de los planos que probablemente encontrará cacofónicos. Esta condición empirista presenta cuatro inconvenientes: se confía excesivamente en la habilidad de una persona como garantía de un trabajo bien hecho, los inspectores de obra no pueden controlar si la ejecución ha sido realizada correctamente, se pueden repetir nuevamente errores de ejecución del pasado, y la falta de registros de ejecución no permite la divulgación de la obra para la mejora de las prácticas profesionales y la formación de nuevos profesionales.

\section{Frágil materialidad}

El deterioro es parte de la naturaleza del adobe y cualquier intento de preservación es casi una contradicción (National Parks Service [NPS], 1978). El Servicio de Parques Nacionales de los Estados Unidos resume en tres puntos como entender las construcciones de tierra: aceptar el material y su deterioro natural, comprender el edificio como un sistema, y entender que las fuerzas de la naturaleza buscan devolver el edificio a su estado original (1978). La fragilidad significa una pesada carga por el mantenimiento 


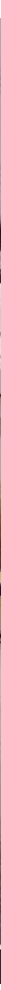

que requiere, pero al implementarlo se retrasa la descomposición natural y se garantiza una extensión de la vida útil de la estructura. Por ello se debe prestar especial atención a identificar los cambios durante sus primeras etapas: grietas, movimientos diferenciales, erosión, etc.

Un ejemplo ilustrativo es el sitio arqueológico inca de Puruchuco: su equipo de mantenimiento todas las tardes recorre los rincones del lugar con un balde de barro preparado para reparar las pequeñas grietas y desprendimientos que han sucedido durante la jornada, una práctica que se da de manera periódica en la arquitectura vernácula. Existe la posibilidad que esta práctica se considere un atentado contra la autenticidad del monumento, tema que Plutarco exploró en Vidas Paralelas (96-117 d.C.) con la Paradoja de Teseo como ejemplo del dilema de la autenticidad, y la relación entre materia y memoria. Plutarco cuenta que el barco de Teseo fue conservado como testimonio de la epopeya de liberación de Atenas del yugo de cretense tras la derrota del minotauro. Con el paso del tiempo, las tablazones eran remplazadas una a una a medida que se deterioraban, creando una discusión entre los filósofos que debatían si aún se trataba de la misma nave, preguntándose qué hubiese pasado si con los maderos retirados se hubiese construido un nuevo barco: ¿Sería este el auténtico, o lo serían ambos?.

Los expertos podrán encontrar en Puruchuco un ejemplo de la paradoja de Teseo, donde con el tiempo se incurrirá, si es que no se ha hecho ya, en modificaciones que van a alterar la configuración de la obra de manera significativa. En una edificación de tierra toda nueva intervención es invasiva, no es reversible, y su futura erradicación no puede ser posible (Tolles et. al., 2002). Una intervención no reversible se convierte en una alteración permanente y por ende en parte de la historia del edificio. Esto lleva a pensar que el trabajo de intervención que se esperaba estuviese inspirado en la filosofía de estabilización de Ruskin (ver Figuras 11 y 12) en realidad se enmarca en la de reintegración de Eugene Viollet-le-Duc (ver Figura 13). El Documento de Nara interpreta lo dicho respecto de la autenticidad en la Carta de Venecia, y reconoce el valor
Figura 15. Detalle de anclaje de canes nuevos y antiguos con piezas metálica del Balcón Cassinelli (s. XIX) en la esquina de los Jirones Trujillo y Tumbes. Restauración de Héctor Abarca y Enrique Guamán financiada por Seguros Royal SunAllaince, 2003. Fotografía por Héctor Abarca.

Figura 16. Ensayos sobre el comportamiento de las sales en la piedra. Laboratorio del Instituto de Conservación Getty, Los Ángeles, 2014. Fotografía por Héctor Abarca. 


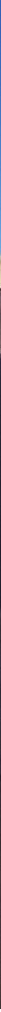

chada antes de su ejecución ${ }^{26}$ (Association of Professional Engineers and Geoscientists of British Columbia \& Architectural Institute of British Columbia, 2012). La fabricación de prototipos ayuda a detectar a tiempo las deficiencias imprevistas que se dan en la etapa de diseño, fabricación e instalación para realizar correcciones y verificaciones de manera fácil y económica. Su uso es habitual en los proyectos que presentan soluciones de fachada ventilada y cortina de vidrio que incluyen muchos componentes y son de diseño inusual. En los proyectos de conservación y restauración se repite el caso de la unicidad y la multiplicidad de elementos; la evaluación de su performance podría permitir añadir elementos adicionales para garantizar una vida más larga a la edificación. Como ejemplo se podría estudiar la inclusión de botaguas en el coronamiento de un muro, parapeto o alféizar; evidentemente este elemento no es parte de la obra original, como tampoco lo son el vidrio flotado y los preservantes de madera, pero pueden ser utilizados si se detallan correctamente y son evaluados. Otros punto crítico se da en los sobrecimientos, que son susceptibles de llevar humedad por capilaridad a los muros que soportan; este fenómeno se puede controlar de varias maneras, ya sea aislando con grava los cimientos del terreno natural, impermeabilizando con barreras de vapor, membranas bituminosas o empleando geocompuestos de drenaje y añadiendo un tubo de avenamiento. Las recomendaciones para mejorar el desempeño arquitectónico de las edificaciones históricas han sido recogidas por varios manuales de soluciones para obras de conservación como Canadian Heritage Preservation: a Manual of Building Conservation de Eric Jokinen (1987) o Recomendaciones Técnicas: Reparaciones de Construcciones de Adobe y Quincha Dañados por Movimientos Sísmicos del Ministerio de Vivienda del Perú (1974).

Los muros de tierra tienen la característica de comportarse estructuralmente como una masa; poseen baja resistencia a la fuerza de comprensión y ductilidad casi nula, razón que se esgrime para explicar su mal comportamiento sísmico (Tolles et. al., 2002). Durante un sismo el muro de tierra puede soportar cargas verticales siempre y cuando no pierda su verticalidad. En las construcciones históricas los muros son muy gruesos y permanecen en pie aún cuando estén severamente agrietados; sin embargo, la fuerza
Figura 19. Refugio de Emergencia modelo en el Instituto Cal-Earth creado por el arquitecto iraní Nader Khalili y de amplio uso en zonas de desastre. Hesperia, 2014. Fotografía por Héctor Abarca.

26. Los mock ups o prototipos pueden ser de dos tipos: el visual mock up (VMU) tiene la función de reproducir todos los detalles arquitectónicos para un valoración estética, mientras que el performance mock up (PMU) sigue con mayor rigurosidad los procesos constructivos y es sometido a ensayos, por lo general permeabilidad al aire, resistencia al agua e integridad estructural, previstos por las especificaciones técnicas del proyecto de acuerdo con las regulaciones del país de referencia. 
devenir Vol. 4, N8, JULIO - DICIEMBRE 2017, pP. 49-74 - Estudios I ISSN 2312-7562 I E-ISSN 2616-4949

UNIVERSIDAD NACIONAL DE INGENIERÍA, LIMA

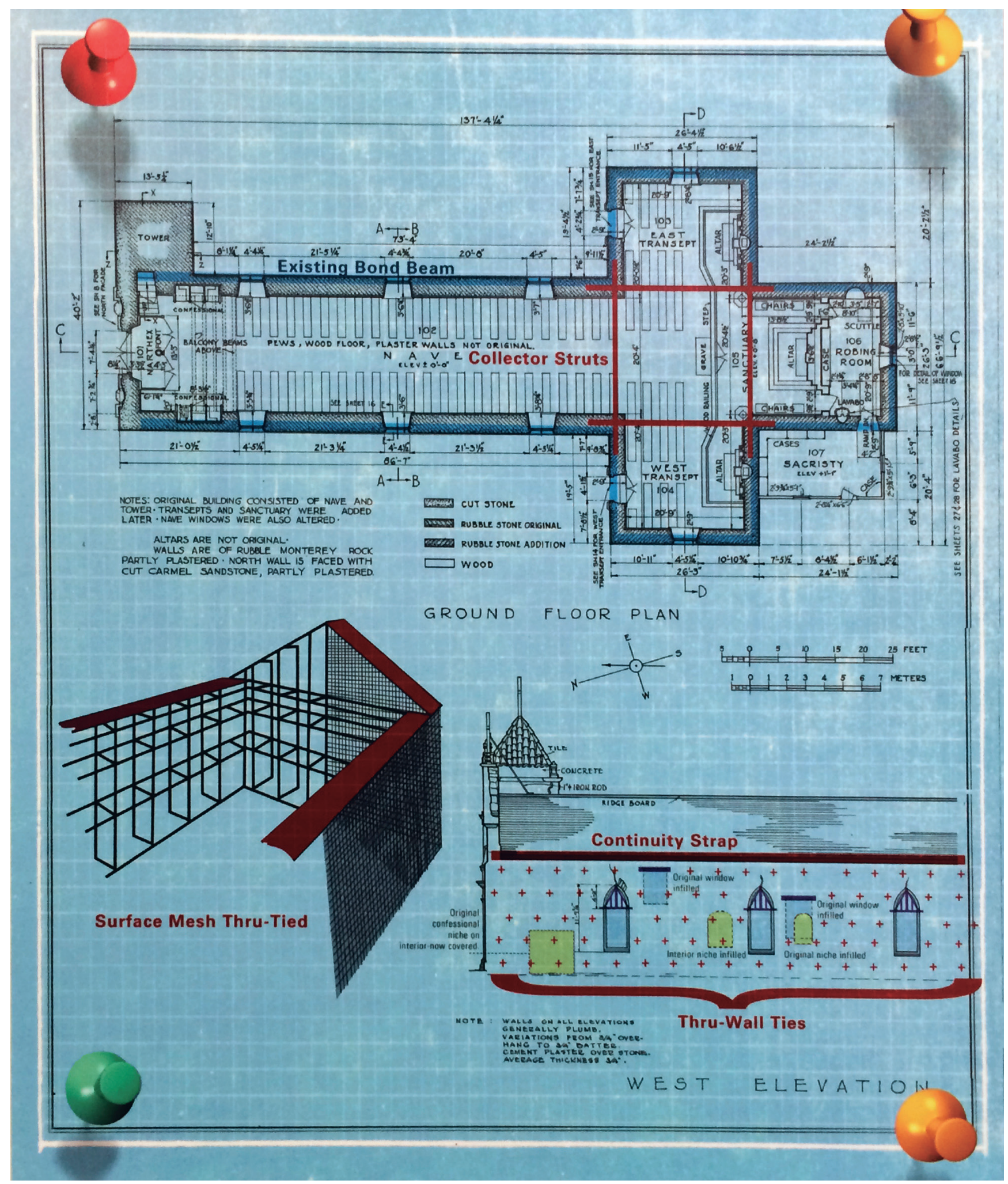

Figura 20. Los esquemas de la intervención estructural muestran el uso de malla metálica y varillas de acero inoxidable y enlucido de cal en la restauración de la Catedral de San Carlo Borromeo, antigua capilla del Real Presidio de Monterey (1792-96), Restauración de Anthony Crosby (1997-2008). Museo Central Patrimonial de la Catedral de Monterey, 2015. Fotografía por Héctor Abarca. 
de tracción de sus elementos individuales, que ya es baja, se pierde cuando aparecen las primeras grietas y no es posible recuperar la fuerza perdida al remplazar las unidades dañadas, como en el caso de la albañilería de ladrillo, aunque esta sea una práctica común en la restauración de muros de adobe.

Entre 1992 y 2002 el proyecto Getty Seismic Adobe Project (GSAP) desarrolló un sinnúmero de ensayos de alternativas no invasivas de estabilización sismorresistente contemporánea para edificaciones patrimoniales de tierra, que se compilaron en el libro Seismic Stabilization of Historic Adobe Structures (Toles et. al., 2000). Los estudios consideran propuestas como la instalación de tirantes de acero inoxidable, ángulos de platinas, amarres de varillas de acero al nivel de la viga collar, pórticos metálicos independientes, siendo uno de los más interesantes el que propone diafragmas de triplay contrachapado siguiendo el perímetro de los entrepisos y techos de acuerdo al modelo de las construcciones de entramado de madera o platform frame, típicos de la arquitectura residencial norteamericana. Una de las soluciones estudiadas se llegó a implementar en la restauración de la casa Del Valle Adobe, que es parte de la Misión de San Fernando, en Los Ángeles, luego del terremoto de Northridge de 1994 (Tolles et. al., 2000).

\section{I+D = La Cátedra Roselli}

El éxito del programa de vivienda económica Elemental en Chile se dio porque la propuesta arquitectónica, las famosas medias casas incrementales diseñadas por Alejandro Aravena e inspiradas en PREVI, está unida a un modelo de gestión e investigación sostenible desarrollado gracias a una serie de alianzas a nivel internacional, con la Universidad de Harvard y el David Rockefeller Center for Latin American Studies, y a nivel local con la Universidad Católica de Chile y la Compañía de Petróleos de Chile, a las que luego se unieron otras empresas, como Sodimac y Codelco. Esta mancomunidad de cooperación es posible a través del Fondo de Fomento al Desarrollo Científico y Tecnológico (Aravena \& lacobelli, 2016), el brazo de la Comisión Nacional de Investigación Científica y Tecnológica (Conicyt) de Chile dedicado al financiamiento de proyectos de investigación y desarrollo (I+D) orientados al desarrollo de proyectos de gran impacto económico y social con la promoción de alianzas público-privada-académica (Conicyt, $\mathrm{s}, \mathrm{f}$, ), y ha permitido la creación de la Cátedra Elemental - Copec en la Universidad Católica de Chile (Aravena \& lacobelli, 2016) para llevar adelante las investigaciones para los siguientes proyectos de vivienda Elemental con total autonomía financiera.

Los proyectos I+D son parte de las políticas estatales que buscan unir áreas de la investigación en Ciencia e Ingeniería en relación a un objetivo productivo. En el caso de este estudio, estas áreas son la tecnología de la construcción en tierra, contemporánea e histórica; la ingeniería sísmica; la extensión de la vida útil de la obra restaurada; y la gestión del patrimonio. En el Perú el Consejo Nacional de Ciencia, Tecnología e Innovación Tecnológica (Concytec) es la agencia oficial que maneja los proyectos I+D. Juntos, el Concytec y el Ministerio de Cultura están en la capacidad de organizar la implementación de un proyecto I+D que saque provecho de los convenios internacionales existentes de investigación en conservación del patrimonio construido. Sobre la base de las sugerencias para países sísmicos que Feilden publicó en Entre Dos Terremotos: Los Bienes Culturales en Zonas Sísmicas $(1987)^{27}$, la PUCP y el Instituto Getty vienen trabajando hace varios años en el desarrollo de modelos de tecnología tradicional que permitan mejorar el comportamiento estructural de la obra histórica de tierra con el objetivo de crear un catálogo de soluciones probadas que constituirán un manual de instrucciones de intervención y fácil mantenimiento $(\mathrm{GCl}, 2016)$. Para ello cuentan con los estudios que Julio Vargas Neumann, Marcial Blondet, Daniel Torrealva y Sofía

27. Título publicado simultáneamente en español e inglés. 
Rodríguez Larraín vienen desarrollando en la PUCP ${ }^{28}$ (ver Figura 18). El WMF también lleva trabajando muchos años en el Perú: cuando el Centro de Investigación y Asesoría Poblacional (CIDAP) nominó el Centro Histórico de Lima a la lista de patrimonio en riesgo World Monument Watch 2008 (CIDAP, 2008), este acto desencadenó un proyecto multipartito en el que se unieron fuerzas con la Agencia de Cooperación Española, la Universidad de Roma La Sapienza y la Universidad Nacional de Ingeniería (UNI) para desarrollar en conjunto la exposición itinerante Historic Center of Lima, a Living City"2, y el proyecto de restauración física y social de la Casa de Las Columnas en 2010 (WMF, 2012). Estas dos experiencias son muestra de cómo al alimón los profesionales peruanos y extranjeros son capaces de llevar adelante proyectos complejos, en contextos desafiantes, que exigen resultados académicos y sociales avanzados. Las conclusiones han sido compartidas, publicadas y aplaudidas en el circuito internacional de conservadores que ronda alrededor del Comité Científico Internacional de Arquitectura Patrimonial de Tierra (ICOMOS-ISCEAH), del que forman parte expertos del Instituto Getty, el WMF, la PUCP y el Centro de Investigación Aplicada en Tierra (CRAterre), quienes junto a la Escuela Nacional de Arquitectura de Grenoble desde 1972 organizan los congresos mundiales de arquitectura de tierra TERRA. ${ }^{30}$

Es lamentable que en estos esfuerzos la presencia del gobierno no sea activa. Por ello se requerirá del liderazgo del Concytec para la coordinación y búsqueda del socio ideal en el sector privado, siguiendo el modelo de Elemental y Conicyt, para darle continuidad a los estudios y dejar de depender totalmente del financiamiento extranjero que no siempre está en concordancia con los intereses nacionales. Con los aportes públicos y privados se deberá crear un centro de estudios que llamaremos Cátedra Bruno Roselli y habría de implementarse tanto en la PUCP como en la UNI, y sería el lugar donde se realicen, evalúen, publiquen y diseminen estudios sobre la mitigación de los daños naturales (terremotos, deslizamientos, inundaciones, polución) y antropogénicos (robo, incendio, abuso de los turistas) en la obra patrimonial de tierra, y a la vez se desarrollen políticas de promoción, herramientas legislativas y financieras pensadas para promover una visión moderna, técnica y social del monumento que no olvide que el patrimonio es un bien público ${ }^{31}$ y una herramienta de gestión de la ciudad. Esta cátedra será un homenaje al ideal de Bruno Roselli y la tarea sisifiana iluminada por el fuego fatuo que desató la pira funeraria de sus amados balcones.

\section{Estudios comparados}

Estudiar comparativamente las experiencias extranjeras permite explorar nuevas alternativas y aprender de la experiencia que otros han desarrollado al resolver problemas comunes (ver Figura 20). La Municipalidad de Quito ve la ciudad holísticamente e interviene tanto en las áreas monumentales como en zonas de menor valor monu-

28. Los trabajos de Vargas Neumann, Blondet y Torrealva respecto al adobe histórico son amplios. Van desde las contribuciones de Vargas Neumann y Blondet al proyecto GSAP a la actual participación de Torrealva al proyecto SRP junto al GCl y la Universidad de Minho. Rodríguez Larraín coordina del Centro Tierra, centro de investigación de la PUCP que estudia la edificaron en tierra en un ámbito histórico, contemporáneo y social. Juntos o por separado todos ellos participan activamente presentando ponencias en conferencias internacionales, como consultores científicos internacionales y en actividades del ICOMOS-ISCEAH.

29. La exposición se presentó en varias ciudades del Perú, Ecuador, España e Italia. Los paneles están disponible en: https://www.wmf.org/sites/default/files/article/pdfs/Lima-Exhibition-Panels.pdf

30. Hay más instituciones dedicadas al estudio de la arquitectura de tierra. Otra que podríamos mencionar es el Instituto Californiano de Arte y Arquitectura de Tierra (Cal-Earth) (ver Figura 19).

31. La noción de bien público se basa en los principios de no exclusión y no rivalidad, lo que significa que así se desee, nadie puede ser excluido de su consumo y el consumo de uno no interrumpe el del otro, en total oposición al bien privado. La gestión cultural ha tomado prestado el concepto de bien público desarrollado inicialmente por James M. Buchanan The Demand and Supply of Public Goods (1968) para, en este caso, colocar al patrimonio histórico al alcance de todos así se trate de una propiedad privada. 
mental, con proyectos de vivienda económica a través de la Empresa de Desarrollo del Centro Histórico de Quito (2001). Sus programas de rehabilitación de cubiertas y fachadas cubren el $100 \%$ de las intervenciones, hasta un monto de 15 mil dólares, de los que el propietario rembolsará el $50 \%$ en un plazo de diez años (IMP, s.f.). El caso italiano es similar: el Estado puede asumir el 50\% del costo de conservación y en casos especiales hasta el $100 \%$, a condición de que el inmueble esté abierto al público (Ministero dei Beni e dell'Attività Culturali e del Turismo, s.f.). Los Bienes de Interés Cultural españoles también requieren que las obras declaradas monumento se abran al público al menos durante dos días al año, ${ }^{32}$ e igualmente lo requiere la ley norteamericana; sin embargo, en este caso únicamente se da si el propietario recibe dinero público. La Ley General del Patrimonio Cultural de la Nación (2007) peruana contiene prerrogativas para exigir trabajos de restauración y el libre acceso al bien monumental, pero no se han reglamentado formas de hacerlas efectivas.

Las leyes de protección del patrimonio en los Estados Unidos y Canadá fallan al proteger la obra privada, por considerarse que su declaración puede limitar los derechos de propiedad (NPS, s.f.b; Canada's Historic Places, 2010). Aunque cada provincia o estado cuenta con legislaciones independientes, es a nivel municipal, a través de los licencias de construcción, donde se hace posible ejercer cierto nivel control sobre las modificaciones a la propiedad histórica que se da en conjunción con propuestas creativas para su protección. Por ejemplo, la ciudad de Vancouver ofrece el programa Restore It ${ }^{33}$, que otorga ayudas para la reparación o reelaboración de elementos singulares

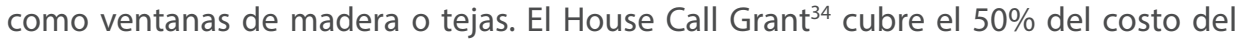
desarrollo de un plan de mantenimiento, y otro tanto del proceso de nominación al registro patrimonial de la ciudad (Vancouver Heritage Foundation [VHF], s.f.a). Cuando la demolición es inminente la VHF colecciona los elementos que pueden recuperarse y los ofrece para ser reutilizados en futuras renovaciones (VHF, s.f.b).

En los Estados Unidos el New York Landmark Conservancy (NYLC) ofrece ayuda en barrios pobres para realizar levantamientos para el registro de las propiedades y ambientes históricos (NYLC, s.f.a), y otorga préstamos blandos para ejecutar proyectos de conservación. El uso de estos beneficios queda documentado en la partida registral y detiene al propietario en caso que quisiese realizar la venta del inmueble y usufructuar del dinero público, a menos que devuelva el préstamo o la deuda prescriba cuando haya pasado el plazo acordado (Savage \& Harper, 1993). El Emergency Grant Program ${ }^{35}$ ofrece una respuesta rápida ante los riesgos que puedan poner en peligro a las personas, fuera y dentro de la edificación, la estabilidad estructural o la integridad arquitectónica del exterior y de los elementos interiores importantes (NYLC, s.f.b).

Los proyectos de mayor envergadura requieren de presupuestos estables; por ello, la Ley de Patrimonio Histórico español desde 1985 establece la obligación de destinar una partida no menor del $1 \%$ de los contratos de obras públicas a trabajos de conservación, enriquecimiento del patrimonio histórico español o al fomento de la creatividad artística, de preferencia en la propia obra o en su entorno inmediato. Dichos fondos puede ser dispuestos por los gobiernos locales, comunidades autónomas, diputaciones forales y provinciales, universidades y fundaciones (Ministerio de Educación Cultura y Deporte, s.f.). En Italia el célebre Istituto Superiore per la Conservazione ed il Restauro, creado por Giulio Carlo Argan y Cesare Brandi, es el brazo técnico y

\footnotetext{
32. En el caso de la autonomía de Andalucía, los BIC deben abrirse al menos cuatro veces al mes (Ley de Patrimonio Histórico de Andalucía, p. 207).

33. Restáuralo. Traducción del autor.

34. Ayuda Visita Médica. Traducción del autor.

35. Programa de Ayudas de Emergencia. Traducción del autor.
} 
científico del Ministerio de Bienes, Actividades Culturales y Turismo, y está financiado por fondos asignados del juego de lotería (MBACT, s.f.). En otros casos la propia designación patrimonial tiene un valor económico: un bien listado en el National Register of Historic Places Program ${ }^{36}$ de los Estados Unidos abre la puerta a la inversión pública que a su vez atrae inversionistas privados (NPS, 2002).

Muchas veces la inversión viene del tesoro público; pocos saben que en los E.E.U.U. el California Mission Preservation Act ${ }^{37}$ (2004) provee 10 millones de dólares cada cinco años a la California Missions Foundation para desarrollar proyectos relacionados a la preservación de las misiones, incluyendo la rehabilitación estructural y la conservación de artefactos. Ante esta ley no importa quién es el propietario: al día de hoy la mayoría de las misiones se han devuelto en propiedad a la Iglesia católica.

La ley peruana es muy clara en identificar la propiedad de la Iglesia como privada, y así evitar cualquier responsabilidad que su protección implique, y repite constantemente el rol contralor de Ministerio del Cultura (Ley General, 2007). ${ }^{38}$ Como la legislación italiana, la peruana ve al patrimonio como un bien público y tiene el derecho de obligar al propietario a participar de la restauración de su propiedad; sin embargo, es injusto limitar el derecho del propietario al uso irrestricto de su bien sin ofrecerle alternativas de financiamiento y herramientas de gestión, maniatándolo con respecto a una propiedad que día a día pierde valor. Así, los caminos a tomar para liberarse de las obligaciones ante la ley son la lenta espera a un colapso natural a causa del abandono o un litigio judicial con el Estado. El Ministerio de Cultura se excusa legalmente de invertir en obras privadas declaradas patrimonio de la nación, pero a la vez el reglamento de la ley moviliza a los organismos competentes a elaborar estrategias, en coordinación con otras entidades del Estado, el sector privado y los organismos internacionales (Ley General, 2007). Es en este marco donde se podría trabajar en implementar la Cátedra Roselli; no será sencillo, pues hay que cambiar la visión anticuada del Estado ante el patrimonio como un objeto inmóvil, un obstáculo para la inversión y una carga legal, y a la vez reformar la visión paternalista de la ciudadanía ante el patrimonio como una labor del Estado. Bruno Roselli dijo en 1958 que habrían de pasar 50 años para que finalmente le demos razón, y luego de 60 años repetimos la misma respuesta que Salazar Bondy dio en aquel entonces. "¿No cree usted que podríamos dársela ahora mismo?" (Salazar Bondy, 1958a, p. 10).

“Usted y yo seremos la semilla. La cruzada rebrotará como los árboles luego de la poda: más fuerte que antes. Creceremos, formaremos un ejército de soñadores. Devolveremos a Lima la gracia y la majestad que le corresponden por tradición y por historia..."

Aldo Brunelli en El Loco de los Balcones

(Mario Vargas Llosa, 1993, p. 99).

\section{Referencias}

Aarhenius, T. (2012). The fragile monument on conservation and Modernity. Londres, Reino Unido: Artífice.

Andrews, D., Bedford, J., \& Bryan, P. (2015). Metric survey specifications for cultural heritage. Londres, Reino Unido: Historic England Publishing.

\footnotetext{
36. Registro Nacional de Lugares Históricos. Nombre oficial en español.

37. Ley de Preservación de la Misiones de California. Traducción del autor.

38. Como aclaración ante una posible confusión: La norma de aprobación de la Ley General del Patrimonio Cultural de la Nación 28296 fue publicada en el Diario Oficial El Peruano el 1 de junio de 2006 y el reglamento el día 2 de junio de 2006. La consulta a dichos documento se ha realizado en la publicación Ley General del Patrimonio Cultural de la Nación 28296 y su Reglamento que realizó el INC en 2007.
} 
Andrews, D., Blake, B., Fradgley, S., \& Roberts, P. (2005). The presentation of historic building survey in $C A D$. Londres, Reino Unido: English Heritage Publishing.

Ángel, G. (1925). Fusión hispano indígena en la arquitectura colonial. Rosario, Argentina: La Casa del Libro.

Aravena, A., \& lacobelli, A. (2016). Elemental: incremental housing and participatory design manual. Ostfildern, Alemania: Hatje Cantz Verlag.

Association of Professional Engineers and Geoscientists of British Columbia \& Architectutal Association of British Columbia. (2012, octubre). Professional Practice Guidelines Building Enclosure Engineering Services. Recuperado de https://www.apeg.bc.ca/getmedia/57d1ac24368d-4800-a671-726c64d82a3f/APEGBC-Building_Enclosure_Guidelines.pdf.aspx

[Belaúnde, F.] (1945, setiembre). Noticiario: Visita del Arquitecto norteamericano Richard J. Neutra. El Arquitecto Peruano, 98, s/p.

Boubeta, J. M. (2008). La rehabilitación actual: diagnostico e intervención. Madrid, España: Colegio Oficial de Aparejadores y Arquitectos Técnicos,

California Building Standards Commission. (2016). California Historical Building Code 2016. Washington, D.C.: International Code Council. Recuperado de https://codes.iccsafe.org/public/ document/details/toc/664

California Mission Preservation Act. (2004). Recuperado de https://www.congress.gov/108/ plaws/publ420/PLAW-108publ420.pdf

Canada's Historic Places. (2010). Standards and Guidelines for the Conservation of Historic Place in Canada. Gatineau, Canadá: Parks Canada.

Comisión Nacional de Investigación Científica y Tecnológica. (s.f.). Fondo de Fomento al DesarroIlo Científico y Tecnológico. Recuperado de http://www.conicyt.cl/fondef/

Consejo de Europa. (1975) Declaración de Ámsterdam. Congreso de Patrimonio Arquitectónico Europeo. Ámsterdam, Holanda.

Consejo de Europa. (2005, octubre 27). Framework Convention on the Value of Cultural Heritage for Society. Faro, Portugal.

Corten, J.-P., Geurts, E., Meurs, P., \& Vermeulen, R. (2014). Heritage as an asset for inner-city development: An urban manager's guide book. Rotterdam, Países Bajos: Nai010 Publishers.

Crespo, M. D. (2006). Arquitectura doméstica de la Ciudad de los Reyes (1535-1750). Sevilla, España: Consejo Superior de Investigaciones Científicas. doi: 10.5194/isprsannals-II-5-W1-235-2013

Elmore, T., \& Ludeña W. (2014). Lecciones de Arquitectura. Segunda parte: construcción. Lima: Fondo Editorial Pontificia Universidad Católica del Perú.

English Heritage. (2009). Measured and drawn: techniques and practice for the metric survey of historic buildings (2da ed.). Londres, Reino Unido: English Heritage Publishing.

English Heritage. (2011). 3D Laser scanning for heritage advice and guidance to users on laser scanning in Archaeology and Architecture (2da ed.) Londres, Reino Unido: English Heritage Publishing.

Feilden, B. (1987). Between two earthquakes: cultural property in seismic zones. Roma, Italia: ICCROM - Getty Conservation Institute.

Gandreau, D., \& Delboy, L. (2012). World Heritage Inventory of Earthen Architecture. París, Francia: World Heritage Programme on Earthen architecture (WHEAP). - CraTerre - ENSAG.

García Bryce, J. (1980). Historia del Perú: Tomo IX, La arquitectura en el Virreinato y la República. Lima, Perú: Editorial Juan Mejía Baca.

Getty Conservation Institute. (2016, marzo). Seismic Retrofitting Project. Recuperado de http:// www.getty.edu/conservation/our_projects/field_projects/seismic/overview.html

Giovannoni, G. (1925). Questioni di architettura nella storia e nella vita: Edilizia, estetica architettonica, restauri, ambiente dei monumenti. Roma, Italia: Società Editrice d'Arte illustrata.

Goldberger, P. (1990, abril 15). Architecture view: a commission that has itself become a landmark. New York Times. Recuperado de http://www.nytimes.com/1990/04/15/arts/architecture-view-a-commission-that-has-itself-become-a-landmark.html?pagewanted=all 
devenir Vol. 4, N8, JULIO- DICIEMBRE 2017, PP. 49-74 - EstudIOS I ISSN 2312-7562 I E-ISSN 2616-4949

UNIVERSIDAD NACIONAL DE INGENIERÍ, LIMA

González-Varas, I. (2008). Conservación de bienes culturales: teoría, historia, principios y normas. Madrid, España: Cátedra.

Granda, J., Hanley, C., Santana Quintero, M., \& Fai, S. (2014). The church of Santiago de Kuño Tambo. En Mind the gap: crossing borders in heritage and conservation. Simposio de Conservación del Patrimonio conducido en la Universidad de Carleton, Ottawa, Canadá. Recuperado de http://carleton.ca/heritage-conservation-symposium/wp-content/uploads/Mind-theGap-Granda-and-Hanley.pdf

Hayakawa, J. (2010). Restauración en Lima: pasos y contrapasos. Lima: Universidad de San Martín de Porres.

National Parks Service (2017, mayo 4). Heritage Documentation Programs. Recuperado de https://www.nps.gov/hdp/

Heritage Documentation Programs. (2015). HABS / HAER / HALS Photography Guidelines. Washington, D.C.: National Parks Service. Recuperado de https://www.nps.gov/hdp/standards/ PhotoGuidelines.pdf

Hernández, J. M. (2013). Autenticidad y monumento: del mito de Lázaro al de Pigmalión. Madrid, España: Abada.

Historic American Buildings Survey. (2008a). American place: the Historic American Buildings Survey at seventy-five years. Washington, D.C.: National Parks Service. Recuperado de https:// www.nps.gov/HDP/habs/AmericanPlace.pdf

Historic American Buildings Survey. (2008b). HABS Guidelines recording historic structures and sites with HABS measured drawings. Washington, D.C.: National Parks Service.

Historic American Buildings Survey. (s.f.). HABS Guide to field documentation. Washington, D.C.: National Parks Service. Recuperado de https://www.nps.gov/hdp/standards/habsfieldguide.html

ICOMOS. (1964). Carta Internacional sobre la Conservación y la Restauración de Monumentos y Sitios (Carta de Venecia 1964). II Congreso Internacional de Arquitectos y Técnicos de Monumentos Históricos, Venecia, 1964.

ICOMOS. (1994). Conferencia de Nara sobre Autenticidad. Nara, 1994. Recuperado de http://www. icomoscr.org/doc/teoria/DOC.1994.nara.documento.sobre.autenticidad.pdf

ICOMOS. (1996). Principios para la Creación de Archivos Documentales de Monumentos, Conjuntos Arquitectónicos y Sitios Históricos. Sofía, 1996. Recuperado de www.icomos.org/charters/ Span.\%20Principios.doc

Instituto Metropolitano del Patrimonio. (s.f.). Programas de Inversión para Edificaciones Patrimoniales del Distrito Metropolitano de Quito. Recuperado de http://www.patrimonio.quito.gob. ec/index.php/servicios-ciudadanos/recupera-tu-casa

Jokilehto, J. (2004). A history of architectural conservation. Oxford, Reino Unido: Elsevier, Butterworth-Heinemann.

Jokinen, E. P. (1987). Canadian heritage preservation: [a manual of building conservation]. Edmonton, Canadá: Lone Pine.

Kubler, G. (1963). The shape of time: remarks on the history of things. New Haven: Yale University Press.

Lamprakos, M. (2014, otoño). Riegl's "Modern Cult of Monuments" and the problem of value. Change over Time, 4.2, 418-435.

Lane, R. (2016). Understanding historic buildings: a guide to good recording practice. Londres, Reino Unido: Historic England Publishing.

Letellier, R., LeBlanc, F. \& Schmid, W. (2007). Recording, documentation, and information management for the conservation of heritage places: guiding principles. Los Ángeles: Getty Conservation Institute.

Ley del Patrimonio Histórico de Andalucía. (2007). Recuperado de http://www.juntadeandalucia. es/boja/2007/248/1 
Ley General del Patrimonio Cultural de la Nación 28296 y su Reglamento. (2007). Recuperado de http://www2.congreso.gob.pe/sicr/cendocbib/con2_uibd.nsf/562A9CCF932F0F62052577E300711E65/\$FILE/2Ley_28296.pdf

Library of Congress. (s.f.) Historic American Buildings Survey/Historic American Engineering Record / Historic American Landscapes Survey. Recuperado de http://www.loc.gov/pictures/collection/hh/

Lima S.O.S. (1966, 29 de abril). Caretas 329, 14-21.

Lizarzaburu, J. (2014, noviembre 19). Primer monumento histórico demolido tras controvertida Ley 30230.[entrada en el blog Lima Milenaria]. Recuperado de http://limamilenaria.blogspot. $\mathrm{ca} / 2014 / 11 /$ primer-monumento-historico-demolido.html

Ministerio de Educación Cultura y Deporte. (s.f.) ¿Qué es el 1\% Cultural? Recuperado de http://www. mecd.gob.es/mecd/cultura-mecd/areas-cultura/patrimonio/1-cultural/definicion.html

Ministero dei Beni e della Attività Culturali e del Turismo. (s.f.). Il gioco del lotto per L'arte e la cultura. Recuperado de http://www.beniculturali.it/mibac/export/MiBAC/sito-MiBAC/Contenuti/MibacUnif/Comunicati/visualizza_asset.html_477352302.html

Mumford, L. (1924). Sticks and stones: a study of American architecture and civilization. Nueva York: Boni and Liverright.

National Parks Service. (1978). The preservation of historic adobe buildings. Preservation Briefs, 5. Recuperado de https://www.nps.gov/tps/how-to-preserve/briefs/5-adobe-buildings.htm

National Parks Service. (1983). Secretary of the Interior's standards and guidelines for architectural and engineering documentation: HABS / HAER Standards. Washington, D.C.: National Parks Service.

National Parks Service. (2002). Registro nacional de lugares históricos. Washington, D.C.: National Parks Service. Recuperado de https://www.nps.gov/nr/publications/bulletins/spanishbrochure/

National Parks Service. (s.f.a). Historic American Buildings Survey: Guidelines for Historical Reports. Washington, D.C.: National Parks Service. Recuperado de https://www.nps.gov/hdp/standards/HABS/HABSHistoryGuidelines.pdf

National Parks Service. (s.f.b). National Register of Historic Places program: frequently asked questions. Recuperado de https://www.nps.gov/nr/faq.htm.

Neutra, R. (1945). Report on visit of South American republics by Richard J. Neutra, architect, and presidente, US Chapter of the Congrès internationaux d'architecture moderne. Richard and Dion Neutra papers (1925-1970), caja 1429. Charles E. Young Reseach Library, Univesity of Southern California, Los Ángeles.

PB. (2013). Bruno Rossellii. Vassar's Enciclopaedia. Recuperado de https://vcencyclopedia.vassar. edu/faculty/prominent-faculty/bruno-roselli.html

Percy, K., Hanley, C., Santana Quintero, M., Cancino, C., Fai, S., Ouimet, C., Rainer, L., \& Villacorta, L. (2013). Recording earthen architecture at the Peruvian Andes: the case of Kuño Tambo Church's historic wall paintings. ISPRS Annals of the Photogrammetry, Remote Sensing and Spatial Information Sciences, Vol.II-5/W1. XXIV. Simposio, International CIPA 2 - 6 Septiembre 2013, Estrasburgo, Francia. 235-40.

Riegl, A. (1987). El culto moderno a los monumentos. Caracteres y origen. Madrid, España: Visor.

Roselli: Lima está siendo destetada. (1959, julio 26). Diario Última Hora.

Saint, A. (1983). The image of the architect. New Haven: Yale University Press.

Salazar Bondy, S. (1958a, julio 9). ¿Una ciudad de rascacielos?, La Prensa, 10. En Salazar Bondy, S \& Susti, A. (2016). La Ciudad como Utopía: Artículos periodísticos sobre Lima 1953-1965, 165 166. Lima: Fondo Editorial de la Universidad de Lima.

Salazar Bondy, S. (1958b, julio 18). Balcones apolillados y tradición, La Prensa, 12. En. Salazar Bondy, S \& Susti, A. (2016). La ciudad como utopía: artículos periodísticos sobre Lima 19531965, 167-169. Lima, Perú: Fondo Editorial de la Universidad de Lima. 
devenir Vol. 4, N8, JULIO- DICIEMBRE 2017, PP. 49-74 - EstudIOS I ISSN 2312-7562 I E-ISSN 2616-4949

UNIVERSIDAD NACIONAL DE INGENIERÍA, LIMA

San Cristóbal, A. (2010). Arquitectura de Lima en la segunda mitad del siglo XVII. Lima, Perú: Universidad San Martín de Porres.

Savage, B. y Harper, M. (1993). My property is important to America's heritage, what does that mean? Washington, D.C.: National Parks Service. Recuperado de https://www.nps.gov/nr/ publications/bulletins/pdfs/MyProp.pdf

The New York Landmarks Conservancy. (s.f. a). Historic Properties Fund: finding historic restaurations. Recuperado de http://www.nylandmarks.org/programs_services/loans/historic_properties_fund/

The New York Landmarks Conservancy. (s.f.b), Emergency Grant Program (EPGP). Recuperado de http://www.nylandmarks.org/programs_services/grants/emergency_preservation_grants/

Thiel, C., Tolles, E. L., Kimbro, E., Webster, F., \& Ginell, W. (1991). GSAP: Getty Conservation Institute guidelines for seismic strengthening of adobe project: report of first year activities. Los Ángeles: Getty Conservation Institute.

Tolles, E. L., Ginell, W., \& Kimbro, E. (2002). Planning and engineering: guidelines for the seismic retrofitting of historic adobe structures. Los Ángeles: Getty Conservation Institute.

Tolles, E. L., Ginell, W., Kimbro, E., \& Webster, F. (2000). Seismic stabilization of historic adobe structures. Final report of the Getty Seismic Adobe Project. Los Ángeles: Getty Conservation Institute.

Torrealva, D. (2015, mayo 15). Characterization and strengthening of historic adobe structures. Seminar on historical earthen buildings. University of Minho. Recuperado de http://www. msc-sahc.org/upload/docs/Seminars/2015/2_Characterization_and_strengthening_adobe.pdf

UNESCO. (2011) Recomendación sobre el paisaje urbano histórico, con inclusión de un glosario de definiciones. En Actas de la Conferencia General 36a reunión París (Vol.1, pp. 60-65). París, Francia: UNESCO. Recuperado de http://unesdoc.unesco.org/images/0021/002150/215084s. pdf\#page $=65$

Vancouver Heritage Foundation. (s.f.a). Get a grant. Recuperado de https://www.vancouverheritagefoundation.org/get-a-grant/

Vancouver Heritage Foundation. (s.f.b). VHF architectural salvage: architectural salvage sales. Recuperado de http://www.vancouverheritagefoundation.org/special-projects/architectural-salvage/

Vargas Llosa, M. (1993). El loco de los balcones. Barcelona, España: Seix Barral.

Velarde, H. (1937, diciembre). The Adobe. El Arquitecto Peruano, 5, 14-16.

Velarde, H. (1940). Bramante ha estado en Lima. El Circo de Pitágoras. Lima, Perú: Compañía de Impresiones y Publicidad.

World Monuments Fund. (2012), Casa de las Columnas. Social Rehabilitation through Monument Restoration $=$ Casa de las Columnas. Rehabilitación social a través de la restauración de un monumento = Casa de las Columnas. Il restauro come occasione di recupero sociale. En Palmerio, G., Lombardi, A. \& Montuori, P. (Eds). Lima: The historic center. Analysis and restoration - Centro Histórico. Conocimiento y restauración - Centro storico. Conoscenza e restauro (pp. 98-105). Roma, Italia: Gangemi Editore.

Wright, F. L. (1914, mayo). In the cause of Architecture II: "Style, therefore, will be the man, it is his. Let his forms alone". Architectural Record, 35(5), 405-13. 